\title{
Experiências e legado da atenção primária em saúde no enfrentamento da pandemia de COVID-19: como seguir em frente?
}

Rosana Aquino, ${ }^{1}$ Maria Guadalupe Medina, ${ }^{2}$ Daiane Nascimento de Castro, ${ }^{3}$ Cléber Araújo Gomes, ${ }^{4}$ Jesus Enrique Patiño Escarcina, ${ }^{5}$ Elzo Pereira Pinto Junior, ${ }^{6}$ Ana Luiza Queiroz Vilasbôas ${ }^{7}$

1 Médica epidemiologista, doutora em Saúde Pública, pesquisadora do Programa Integrado de Formação e Avaliação da Atenção Básica e docente do Programa de Pós-graduação do Instituto de Saúde Coletiva (ISC) da Universidade Federal da Bahia (UFBA). Membro do Comité gestor da Rede de Pesquisa em Atenção Primária em Saúde (APS) da Associação Brasileira de Saúde Coletiva (Abrasco).

2 Médica, doutora em Saúde Pública, pesquisadora do Programa Integrado de Formação e Avaliação da Atenção Básica e docente do Programa de Pós-graduação do Instituto de Saúde Coletiva (ISC) da Universidade Federal da Bahia (UFBA). Membro do Comité gestor da Rede de Pesquisa em Atenção Primária em Saúde (APS) da Associação Brasileira de Saúde Coletiva (Abrasco).

3 Professora assistente do curso de Medicina do Instituto de Saúde e Biotecnologia da Universidade Federal do Amazonas (UFAM). Enfermeira e sanitarista. Especialista em Gestão da Atenção Básica, mestra em Saúde Comunitária e doutoranda em Saúde Pública pelo Instituto de Saúde Coletiva (ISC) da Universidade Federal da Bahia (UFBA).

4 Professor do Instituto de Saúde e Biotecnologia da Universidade Federal do Amazonas (UFAM). Fisioterapeuta, mestre em Saúde, Ambiente e Trabalho pelo Programa de Pós-Graduação em Saúde, Ambiente e Trabalho (PPGSAT) da Universidade Federal da Bahia (UFBA) e doutorando em Saúde Pública pelo Instituto de Saúde Coletiva (ISC) da UFBA.

5 Médico pela Universidad Nacional de San Agustin de Arequipa-Perú, mestre em Medicina e Saúde pela Universidade Federal da Bahia (UFBA), doutorando no Instituto de Saúde Coletiva (ISC) da UFBA.

6 Fisioterapeuta pela Universidade Estadual do Sudoeste da Bahia (UESB). Mestre em Saúde Coletiva Universidade Estadual do Ceará (UECE). Doutor em Saúde Pública pelo (ISC) da Universidade Federal da Bahia (UFBA). Pós-doutorando em Epidemiologia no Centro de Integração de Dados e Conhecimentos para a Saúde (Cidacs) da Fundação Oswaldo Cruz (Fiocruz) da Bahia.

7 Médica. Doutora em Saúde Pública, professora associada II e pesquisadora do Programa Integrado de Formação e Avaliação da Atenção Básica do Instituto de Saúde Coletiva da Universidade Federal da Bahia (UFBA).

AQUINO, R.; MEDINA, M. G.; CASTRO, D. N. de; GOMES, C. A.; ESCARCINA, J. E. P.; PINTO JUNIOR, E. P.; VILASBÔAS, A. L. Q. Experiências e legado da atenção primária em saúde no enfrentamento da pandemia de COVID-19: como seguir em frente? In: BARRETO, M. L.; PINTO JUNIOR, E. P.; ARAGÃO, E.; BARRAL-NETTO, M. (org.). Construção de conhecimento no curso da pandemia de COVID-19: aspectos assistenciais, epidemiológicos e sociais. Salvador: Edufba, 2020. v. 2. 


\section{Introdução}

A pandemia de COVID-19 desencadeou em todo mundo uma crise sanitária, social e econômica sem precedentes, com impactos devastadores sobre as condições de vida da população. Mais de seis meses após a declaração de Emergência Sanitária de Âmbito Internacional, as análises do panorama mundial demonstraram que o perigo global continuava elevado e a evolução da pandemia será muito longa, sendo imprescindível o fortalecimento de esforços sustentados em nível comunitário, nacional, regional e global. (WHO, 2020b)

A resposta para o enfrentamento da pandemia exige um amplo elenco de intervenções do setor de saúde, abrangentes e coordenadas, envolvendo todos os níveis de atenção, incluindo a vigilância e monitoramento dos casos e controle; a atenção oportuna aos pacientes, de acordo com a gravidade do quadro; e medidas de saúde pública, especialmente, de distanciamento social para conter a transmissão da pandemia na população. A implementação dessas medidas de controle, por sua vez, depende de ação governamental intersetorial abrangendo ações regulatórias sobre os fluxos de circulação de pessoas e mercadorias, regulamentação do uso de espaços públicos e privados e restrições ao funcionamento de diversos setores 
produtivos, dentre outros, assim como políticas econômicas e de proteção social.

A literatura internacional sobre a reorganização dos sistemas de saúde para o enfrentamento da COVID-19 tem destacado a importância da coordenação entre profissionais da Atenção Primária à Saúde (APS) e demais níveis de atenção e da existência de autoridades de saúde pública em todas as esferas de gestão para melhor eficácia das ações de controle da pandemia. (DUNLOP et al., 2020; HOLSTEIN, 2020; JULIA, 2020) O papel de uma APS forte como base para respostas sanitárias eficazes em situações de emergência tem sido enfatizado, dado o amplo espectro de ações contempladas no nível primário de atenção, o que lhe confere uma alta capacidade para atuar no controle de epidemias. (BADRFAM; ZANDIFAR, 2020; DUNLOP et al., 2020; GREENHALGH; KOH; CAR, 2020; HOLSTEIN, 2020; KIDD, 2020)

No caso brasileiro, o governo federal tem se notabilizado internacionalmente pelo negacionismo frente à pandemia, disseminação de mensagens sem base científica e pelas ações cotidianas de destruição de iniciativas de enfrentamento implementadas por estados e municípios (GIOVANELLA et al., 2020; COVID-19..., 2020), conformando um quadro de descoordenação das ações que tem contribuído para o fracasso da resposta nacional, evidenciada pela posição do país entre os primeiros países no mundo em número de casos e óbitos por COVID-19. A adesão da população às medidas de saúde pública, imprescindível para o controle da pandemia, e a organização do sistema de saúde para implementação de ações de vigilância e atenção à população devem ser alvo de políticas públicas e ações governamentais em defesa da vida. A implementação dessa agenda constitui um enorme desafio para a sociedade brasileira no momento atual.

Neste capítulo, a partir da análise crítica de experiências internacionais e de alguns municípios brasileiros, discutiremos 
a importância da reorganização da APS para o enfrentamento da pandemia de COVID-19. Enfatizando a importância do desenvolvimento de um amplo leque de ações de vigilância e cuidado fundamentais para a atenção à saúde da população em modelos de APS como o adotado no Brasil, de base territorial e comunitária, apontaremos os principais entraves a serem superados para garantir as condições adequadas ao desenvolvimento do trabalho das equipes quanto à estrutura das unidades de saúde, proteção aos trabalhadores e da população, reorganização dos processos de trabalho, capacitação das equipes e articulação com toda a rede de atenção do sistema de saúde. Outro capítulo do livro, intitulado "Vigilância Universal da COVID-19 na Atenção Primária à Saúde", discute de forma mais aprofundada a necessária incorporação na APS das ações de vigilância e controle da transmissão do SARS-CoV-2, complementando as reflexões sobre o importante papel da rede de serviços de APS no enfrentamento da pandemia.

\section{Modelo de reorganização da APS para o enfrentamento da pandemia de Covid-19}

A APS constitui a base de uma resposta eficaz dos sistemas de saúde a emergências sanitárias, uma vez que este nível de atenção é a porta preferencial de entrada em sistemas de saúde bem organizados (STARFIELD; SHI; MACINKO, 2005) e, particularmente, em circunstâncias em que as principais medidas de contenção da epidemia envolvem ações populacionais e comunitárias, como o que ocorre no cenário atual. (WHO; UNICEF, 2020) Ressalta-se que a discussão sobre a ação crucial da APS no enfrentamento de epidemias não é novidade no Brasil (BRASIL, 2018) e que, na literatura internacional, há evidências da relação entre resposta sanitária global efetiva e grau de competência da APS, como ocorreu 
especificamente no caso da epidemia de ebola. (BHAUMIK, 2020; DUNLOP et al., 2020; MINUÉ-LORENZO, 2020)

Se no início da pandemia de COVID-19 houve dúvida ou descrédito sobre a importância da APS no seu controle, haja vista a experiência da Espanha (MINUÉ-LORENZO, 2020) ou da Itália (NACOTI et al., 2020), com fechamento de serviços de APS e ênfase predominante na atenção hospitalar, a dura realidade de sobrelotação dos serviços, exaustão dos profissionais de saúde e descontrole na contenção da curva epidêmica rapidamente fizeram com que as estratégias fossem revisadas, apontando-se o papel central a ser desempenhado pela APS na contenção da epidemia. (DUNLOP et al., 2020) A literatura científica internacional e as recomendações de organismos multilaterais têm destacado, desde então, a importância da APS na resposta ao enfrentamento da pandemia, que compreende um largo espectro de ações de vigilância e cuidado. (BADRFAM; ZANDIFAR, 2020; DUNLOP et al., 2020; GREENHALGH; KOH; CAR, 2020; HAINES et al., 2020; HOLSTEIN, 2020; KIDD, 2020; WHO; UNICEF, 2020)

Medina e demais autores (2020) sugerem que as ações de enfrentamento à pandemia no âmbito da APS podem ser classificadas em quatro eixos:

1. vigilância em saúde nos territórios para reduzir o risco de expansão da epidemia: notificação de casos e deteç̧ão de contatos; atividades educativas e de comunicação social para divulgar informações sobre a prevenção de COVID-19, combater fake news e estigma relacionado à doença, e incentivar a adesão a medidas de proteção da população nos territórios e equipamentos sociais (distanciamento social, uso de máscaras e medidas de higiene);

2. atenção aos usuários com COVID-19: acompanhamento sistemático dos casos leves em seus domicílios, com curta periodicidade, monitorando as condições clínicas para identificação 
precoce de sinais de agravamento, com garantia de retaguarda de transporte sanitário e articulação com a atenção especializada e hospitalar; definição de fluxos e canais de comunicação para a garantia de cuidado oportuno;

3. suporte social a grupos vulneráveis: apoio a idosos e outros grupos de risco que apresentem dificuldades de locomoção para obtenção de bens de consumo ou medicamentos; busca de locais alternativos para isolamento - como escolas e hotéis - para situações de precariedade habitacional; incentivo e apoio a alternativas comunitárias para acesso à máscara, materiais de higiene e cestas básicas; apoio ao cadastramento em programas sociais; e

4. continuidade das ações próprias da APS: melhoria da acessibilidade aos cuidados preventivos, de tratamento e reabilitação de forma segura, transmitindo confiança à população na prestação desse cuidado, especialmente, as ações de vacinação, pré-natal e de acompanhamento aos agravos crônicos; renovação de receitas e entrega domiciliar de medicamentos. Partindo das formulações das autoras, elaboramos um modelo de reorganização da APS, apresentado na Figura 1, acrescentando um eixo transversal de ações de fortalecimento do modelo de APS de base territorial e comunitária que sustenta o desenvolvimento de todas as ações propostas, tanto de cuidado individual como a ação coletiva, desenvolvidas nas Unidades Básicas de Saúde (UBS) e nos territórios, de modo a articular satisfatoriamente iniciativas que assegurem a proteção dos indivíduos, suas famílias e da comunidade, especialmente em condições de extrema adversidade. Compõem esse eixo, as ações de readequação do espaço físico das UBS; reorganização dos processos de trabalho das equipes, incluindo alternativas presenciais e remotas utilizando Tecnologias de Informação e Comunicação (TICs) para a manutenção das atividades do cuidado individual - triagem, consultas 
e atendimentos - e nos territórios - visitas e outras ações comunitárias -; adoção de protocolos de proteção e segurança dos profissionais e usuários para atuação nas UBS e nos territórios; articulação com a rede de atenção do Sistema Único de Saúde (SUS) para a vigilância e o cuidado integral e oportuno em todos os níveis; atualização sistemática dos instrumentos de reconhecimento do território - mapeamento, cadastramento do SUS - e fortalecimento dos mecanismos de articulação com a comunidade. 


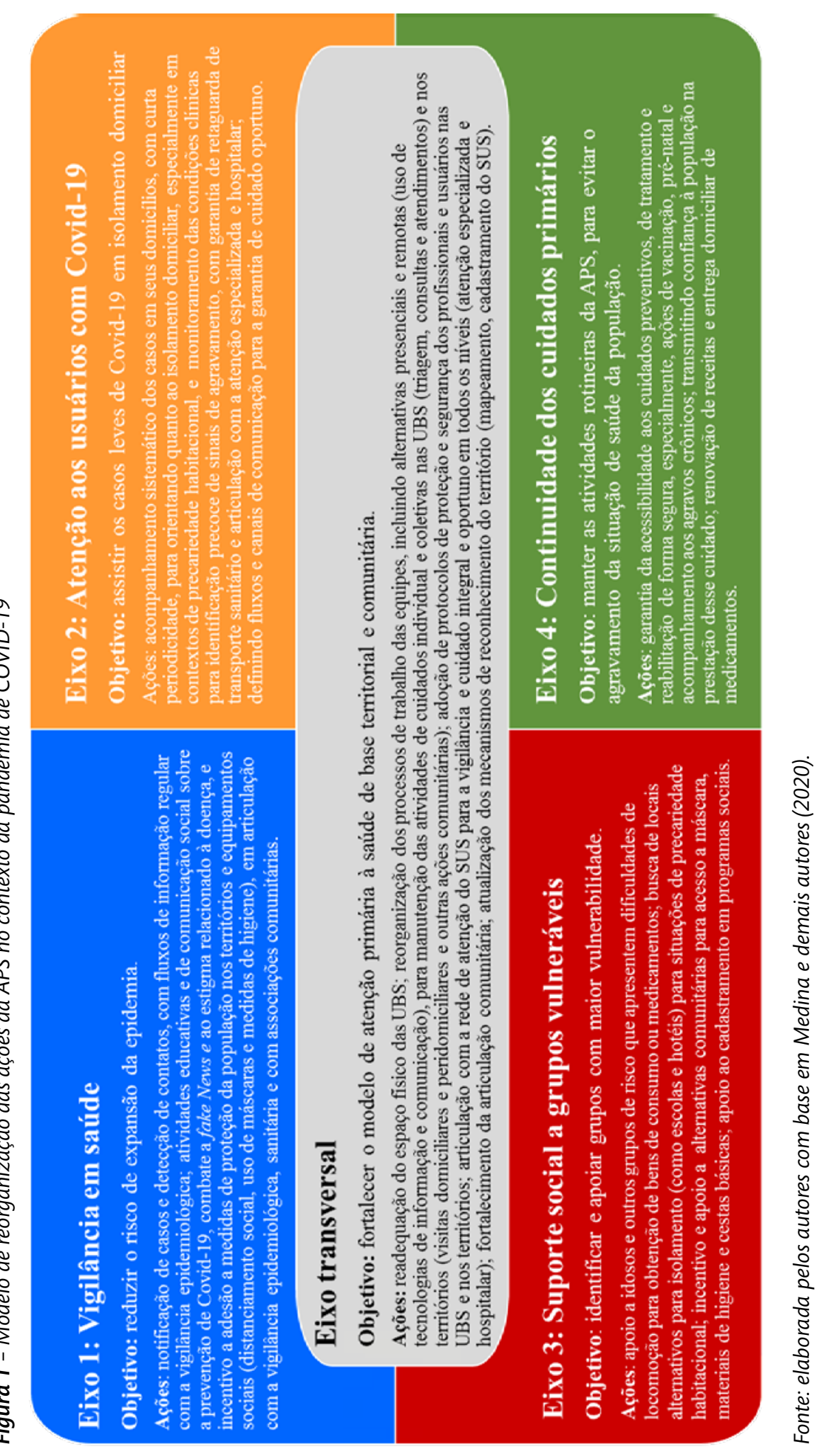




\section{Experiências internacionais de reorganização da APS}

Na maioria dos países analisados, foram inúmeros os desafios para a rápida reorganização das ações e serviços dos sistemas de saúde para o enfrentamento da pandemia, como a sobrecarga dos profissionais, da capacidade dos serviços e desabastecimento de materiais e equipamentos. (CHERSICH et al., 2020; FIORINO et al., 2020; GARG et al., 2020) Por outro lado, as adaptações e inovações implementadas foram impressionantes, e, em alguns casos, com participação fundamental do nível primário de atenção à saúde. (BADRFAM; ZANDIFAR, 2020; DUNLOP et al., 2020; GREENHALGH; KOH; CAR, 2020; HOLSTEIN, 2020; KIDD, 2020)

A experiência de diversos países tem apontado a necessidade de adoção de novas estratégias para gerenciar o atendimento dos pacientes e para identificação oportuna de casos suspeitos e confirmados de COVID-19, sendo fundamental a proteção às pessoas vulneráveis, a continuidade dos serviços regulares de saúde para toda a população e a segurança dos usuários e profissionais de APS. (CHAN et al., 2020; KIDD, 2020; WILLIAMS; TSILIGIANNI, 2020)

Estudos demonstraram o grande risco de contaminação dos profissionais de saúde de serviços de APS dada a grande exposição, especialmente, no início da pandemia. Em uma região da Itália, apenas $46 \%$ dos médicos de APS relataram receber Equipamentos de Proteção Individual (EPIs) e apesar de aproximadamente $40 \%$ apresentarem sintomas sugestivos de COVID-19, apenas 6,6\% realizaram teste de Reação da Transcriptase Reversa seguida pela Reação em Cadeia da Polimerase (RT-PCR), dos quais 11\% testaram positivo. (FIORINO et al., 2020) Os principais problemas apontados foram a insuficiência de equipamentos, de profissionais, sobrecarga física e psicológica, dificuldade de realização de testes e garantia do isolamento precoce dos profissionais com suspeita da 
doença. Países africanos se depararam com problemas adicionais, como o suprimento limitado ou indisponível de condições sanitárias mínimas, como abastecimento de água em diversas cidades, comprometendo a adoção das medidas básicas de prevenção nos serviços pela população. (CHERSICH et al., 2020)

Para prevenção de infecções nosocomiais na APS, além da adequação da infraestrutura das unidades, foram elaboradas diversas recomendações e protocolos para proteção dos profissionais e usuários, atentando para a necessidade de garantir EPIs em número suficiente e adequado às atividades realizadas; ${ }^{8}$ treinamento dos profissionais para o uso dos EPIs; higienização dos ambientes ${ }^{9}$ e a distribuição racional de materiais e equipamentos. (AMBIGAPATHY et al., 2020; CHAN et al., 2020; HOLSTEIN, 2020; MASH, 2020; RAZAI et al., 2020; ZHONGQING, 2020)

As medidas adotadas de reorganização da APS nas experiências internacionais analisadas, tanto para a atenção aos pacientes de COVID-19 como para continuidade de todas as demais ações da APS, foram sistematizadas no Quadro 1 e discutidas nos tópicos a seguir.

8 Em linhas gerais, as recomendações para o uso dos EPIs nos serviços de APS foram: a) todos os profissionais que prestam atendimento clínico: máscara cirúrgica, avental e luvas; b) realização de procedimento que gerem aerossóis: máscara N95, proteção para os olhos, avental e luvas; e c) trabalhadores que higienizam as salas: avental de plástico descartável, máscara facial e luvas.

9 Para higienização dos ambientes, os procedimentos recomendados foram: a) desinfecção de todas as superfícies duras, pisos, cadeiras, maçanetas, acessórios sanitários e equipamentos não invasivos e reutilizáveis com uma solução desinfetante, ou esterilização com luz ultravioleta de uma a três vezes por dia, durante 30 minutos a cada vez; b) descarte de todo o lixo em um saco com identificação de materiais de risco biológico; e c) aplicação dos procedimentos padrão de controle de infecção para gerenciamento de resíduos e transporte, incluindo roupa de cama e lavanderia. 


\section{Atenção aos pacientes com GOVID-19}

Em muitos países, um dos passos iniciais do reordenamento da APS foi a ampla capacitação dos profissionais acerca de manifestações clínicas, critérios para definição de caso, formas de transmissão e prevenção, monitoramento e encaminhamento para os demais níveis do sistema. (CHAN et al., 2020; GREENHALGH; KOH; CAR, 2020; MASH, 2020) Adicionalmente, houve grande esforço para disponibilizar EPI e orientações sobre seu uso, e para elaborar protocolos de atenção à saúde da população. (GREENHALGH; KOH; CAR, 2020; KIDD, 2020)

A organização e as normas para atendimentos presenciais nos centros de APS foram alteradas através de mudanças significativas no processo de trabalho dos profissionais, tanto para atenção à COVID-19 quanto para outras doenças. A substituição de consultas presenciais por teleconsultas via chamada telefônica, de vídeo ou através de outras TICs têm sido a principal modificação dos processos de trabalho na APS (ANDRIKOPOULOS; JOHNSON, 2020; BRESSY; ZINGARELLI, 2020; FIORINO et al., 2020; GILLIES et al., 2020; GRANGE et al., 2020; GREENHALGH; KOH; CAR, 2020; JONES et al., 2020; MARSHAL et al., 2020; RAZAI et al., 2020; TRETHEWEY et al., 2020), ao lado da implementação de sistemas de pré-agendamento (CHAN et al., 2020; ZHONGQING et al., 2020) e triagem prévia de pacientes on-line ou por telefone. (GREENHALGH; $\mathrm{KOH}$; CAR, 2020) A implementação do atendimento remoto, visando conter a disseminação da doença, proteger os profissionais de saúde e manter os cuidados às pessoas que não podem estar no serviço de saúde, alterou o padrão dos atendimentos e possibilitou a oferta de serviços essenciais, especialmente para o cuidado à saúde dos indivíduos mais vulneráveis. (DEWAR et al., 2020; GILLIES et al., 2000; GRANGE et al., 2020; JONES et al., 2020; WILSON; RAMAGE; FAGAN, 2020) 
Na Itália, região da Lombardia, um inquérito com médicos de APS identificou que $87,5 \%$ desses profissionais modificaram sua prática de prestação de cuidados, utilizando telefone $(73,1 \%)$ ou videochamadas (24,4\%). (FIORINO et al., 2020) Da mesma forma, na região de Piemonte, o monitoramento sistemático dos pacientes com COVID-19 foi realizado pela APS através de consultas telefônicas (duas vezes por dia) e de videochamadas nos casos de agravamento de sintomas. (BRESSY; ZINGARELLI, 2020) No Reino Unido, a recomendação inicial foi de que indivíduos com quadros leves de COVID-19 não comparecessem às unidades de saúde e uma das primeiras medidas adotadas foi a utilização de telemedicina. Um levantamento apontou que antes da pandemia mais de $70 \%$ das consultas de APS eram realizadas presencialmente, com redução para $23 \%$ após algumas semanas do início da crise. (ROYAL COLLEGE OF GENERAL PRACTITIONERS RESEARCH; SURVEILLANCE CENTRE, 2020)

Para adoção de estratégias virtuais de atendimento, no Reino Unido, foram estabelecidos protocolos com diretrizes de triagem on-line de pacientes, orientações para escolha do melhor recurso segundo as necessidades dos usuários, e orientações aos profissionais sobre a condução da teleconsulta, realização de exame físico remotamente, notificação e encaminhamentos conforme grau de manifestação da doença. Para os pacientes que moravam sozinhos, foi criada uma rede de segurança e gerenciamento, com identificação de alguém de confiança da comunidade ou da família para acompanhamento contínuo e comunicação com a equipe de saúde. (GREENHALGH; KOH; CAR, 2020) Para algumas situações, foi desenvolvido o "monitoramento móvel de saturação de oxigênio”, no qual um membro da equipe era selecionado para obter uma leitura rápida dos pacientes em domicílio. (MAJEED; MAILE; BINDMAN, 2020) 
As visitas domiciliares foram fortemente afetadas pela pandemia, e em muitos países foram restritas a casos específicos, sendo substituídas por teleatendimento. (MARTÍNEZ-RIERA; GRAS-NIETO, 2020; WILSON et al., 2020) Na França, houve ampliação de competências do enfermeiro domiciliar e foi implantado um serviço de telecare para manejo clínico de pacientes com COVID-19 e orientação sobre prescrições médicas. Quando não era possível o uso de ferramentas on-line, as visitas domiciliares eram garantidas, com adoção de medidas de proteção aos profissionais. (CHAMBOREDON; RAMAN; COLSON, 2020)

No início da pandemia na Espanha, os guias do Ministério da Saúde recomendavam que a APS, em especial a atenção domiciliar, desempenhasse um papel relevante no controle e acompanhamento de pessoas infectadas ou suspeitas e de seus familiares. Entretanto, com o agravamento da crise e decretação de medidas emergenciais, o foco da atenção à saúde foi direcionado para os hospitais e foram fechados diversos centros de APS. Ademais, desde o princípio, foi descartada a perspectiva comunitária da APS e a importância da participação social como instrumento fundamental no controle da pandemia. O modelo hospitalocêntrico e medicalizado adotado negligenciou os recursos valiosos da participação comunitária em colaboração com profissionais de APS para comunicação social e identificação de necessidades advindas do contágio e do confinamento dos indivíduos. (MARTÍNEZ-RIERA; GRAS-NIETO, 2020)

Destaca-se que, especialmente nos países mais pobres, a pandemia aprofundou problemas preexistentes, o que comprometeu a capacidade de atender às novas necessidades. Nos países africanos, os serviços de APS já apresentavam alta demanda, superlotação e insuficiência de recursos humanos, sendo necessário o apoio internacional para provimento de profissionais, observando-se problemas como barreiras linguísticas e baixa adesão da 
população. (CHERSICH et al., 2020) Na Índia, um estudo identificou problemas na preparação das UBS para a pandemia, como: espaço físico limitado, sem separação de portas de entrada e saída (49,0\%); ventilação inadequada (57,0\%); ausência de medidas de controle de infecção no ar (75,5\%); e indisponibilidade de estrutura adequada para lavagem das mãos para os pacientes $(23,5 \%)$. (GARG et al., 2020) Em Singapura e na África do Sul, a coexistência da COVID-19 com outras epidemias, incluindo aquelas com manifestações clínicas semelhantes, como Dengue, Zika e Chikungunya, aumentou a sobrecarrega dos sistemas de saúde, o que deve ter ocorrido em diversos países do mundo. (DAVID; MASH, 2020; LAM; CHUA; TAN, 2020)

\section{Continuidade das ações de promoção,} prevenção e cuidado da APS

O grande aumento da demanda de assistência hospitalar aos pacientes com quadros clínicos graves de COVID-19(GRASSELLI et al., 2020), a adoção de medidas de controle da pandemia, e a consequente redução na oferta de serviços ambulatoriais e hospitalares voltados para outros cuidados de saúde não urgentes (JOY et al., 2020; VERHOEVEN et al., 2020) têm ocasionado impactos negativos na atenção à saúde da população, especialmente, para alguns problemas de saúde e grupos populacionais específicos. Esse cenário foi agravado, no âmbito da APS, tanto pela diminuição na oferta de ações de promoção, preventivas e assistenciais, como pelo adiamento na busca por atendimento pelos usuários, devido às medidas de distanciamento social e a necessidade de adaptações dos estabelecimentos de saúde para evitar contaminação de trabalhadores e usuários. (HUSTON et al., 2020; VERHOEVEN et al., 2020) Mesmo após a superação da fase de maior contágio por COVID-19, os impactos adversos na atenção e na saúde dos indivíduos e suas famílias, que requerem cuidados primários, deverão permanecer, 
especialmente, entre os mais vulneráveis e aqueles portadores de doenças crônicas não transmissíveis.

Nos Estados Unidos, um estudo baseado em registros de mais de 35 milhões de pacientes evidenciou um marcante e rápido declínio no total de consultas ambulatoriais realizadas a partir de março de 2020, período em que o número de casos de COVID-19 começou a crescer de modo acelerado naquele país. Observou-se, também, redução da oferta de consultas, exames ou procedimentos específicos para portadores de doenças crônicas, a exemplo do rastreamento e tratamento de câncer. (ZIEDAN et al., 2020)

A Austrália foi um dos países que apresentou resposta nacional no âmbito dos cuidados primários para proteção às populações vulneráveis, incluindo idosos, pessoas imunossuprimidas, com doenças crônicas ou deficiência e aborígenes, com garantia da continuidade do atendimento e plano de ação que envolveu o financiamento voltado para teleconsultas. (KIDD, 2020) Em Ohio, nos Estados Unidos, a orientação foi reduzir a oferta de atendimento presencial nas unidades de cuidados primários, com reagendamento de visitas e disponibilização do serviço de telessaúde poucos dias após o início da pandemia. A rapidez na adoção dessas tecnologias deveu-se à experiência prévia dos médicos no uso das ferramentas digitais e a mudanças regulatórias que possibilitaram o reembolso pelos planos de saúde. (OLAYIWOLA et al., 2020)

Indivíduos com doenças respiratórias crônicas têm sido alvo de grande preocupação quanto ao risco de infecção ou desenvolvimento de formas graves de COVID-19, assim como devido a potenciais erros de diagnóstico pela sobreposição dos sintomas respiratórios. No Reino Unido, com a suspensão dos check-ups de rotina, novas estratégias digitais para monitoramento e a ampliação das consultas on-line passaram a ser utilizadas para fornecer 
orientações e suporte, incluindo o gerenciamento da ansiedade e medo, potencializados pelo cenário de crise. (COVID-19 HERALDS..., 2020)

Um estudo de revisão sobre o atendimento de pé diabético identificou interrupção considerável na provisão dos serviços na atenção primária e hospitalar durante a pandemia. (JALY et al., 2020) Para garantir a continuidade da atenção aos portadores de diabetes, foram adotadas alternativas para suporte contínuo, através de acompanhamento via telefone, videoconferência ou mesmo visitas domiciliares, além da garantia de acesso à insulina, outros medicamentos e suprimentos. (BERAN et al., 2020)

No Reino Unido, todas as etapas do gerenciamento da atenção aos pacientes com câncer na APS foram afetadas na pandemia. Os programas nacionais de rastreamento, responsáveis por cerca de $5 \%$ do total de casos diagnosticados por ano, foram suspensos, com previsíveis repercussões no diagnóstico precoce, aumentando a importância da suspeita diagnóstica de câncer baseada em sintomas. Entretanto, uma vez que a busca por cuidados primários resulta, dentre outros fatores, da percepção do usuário sobre suas necessidades e sobre as consequências do atendimento, é provável que pacientes com sintomas de alerta bem conhecidos - nódulo ou sangramento retal - continuem a procurar atendimento, mas que sintomas vagos - fadiga, alteração no hábito intestinal e perda de peso - sejam minimizados como triviais. Assim, campanhas de saúde, através da mídia social e redes comunitárias devem ser realizadas para conscientização da importância do diagnóstico sintomático do câncer e da procura de atendimento oportuno. (JONES et al., 2020)

$\mathrm{Na}$ Espanha, um estudo com um painel de especialistas para o manejo da hiperplasia prostática recomendou que no período durante e após a pandemia, o diagnóstico e a prescrição do tratamento devem ser baseados em telemedicina e em protocolos 
conjuntos da APS com especialistas em urologia, e que o tratamento cirúrgico eletivo possa ser adiado, de acordo com as condições de cada paciente, para minimizar os riscos. (MEDINA-POLO et al., 2020) Em Michigam, nos Estados Unidos, os cuidados geriátricos primários presenciais foram drasticamente reduzidos, sendo priorizado apenas casos de urgência, e incorporadas ferramentas digitais na realização de consultas ambulatoriais rotineiras em idosos. A experiência prévia de implantação de um sistema de registro eletrônico de saúde específico foi ressaltada como facilitadora para viabilizar a implementação das teleconsultas e de normas adotadas segundo a gravidade e urgência dos casos. Para incentivar as consultas por videoconferência, foi incorporada uma sala de bate-papo, o Zoom Health, com possibilidade de adicionar familiares, porém, houve resistência dos idosos, que preferiam as consultas via telefone, possivelmente pela dificuldade no uso dessas tecnologias. (DEWAR et al., 2020) O uso de ferramentas digitais também tem sido utilizado como mecanismo de triagem e orientação nutricional remota na APS, com o intuito principal de identificar disfunções nutricionais e definir planos terapêuticos. (KRZNARIĆ et al., 2020)

Os serviços de assistência farmacêutica também foram impactados pela COVID-19 e passaram por grandes adaptações. Na Espanha, foram implementadas mudanças em toda a rede de saúde com ampliação dos serviços de farmácia hospitalar, como a telefarmácia, em articulação com a APS. As estratégias adotadas foram a dispensação dos medicamentos com hora marcada nas unidades para todos os pacientes ambulatoriais e entrega domiciliar para usuários com limitação de deslocamento. (MARGUSINO-FRAMIÑÁN et al., 2020) O provimento de medicamentos na Cidade do Cabo, organizado segundo áreas geográficas e planejado por farmacêuticos, contou com transporte estatal e rede de voluntários para a distribuição nos territórios. A entrega dos medicamentos aos pacientes 
passou a ser feita nos domicílios por agentes comunitários de saúde, que, na oportunidade, também realizavam rastreio de sintomas de COVID-19 e identificação de riscos de contágio. (BREY et al., 2020)

As reestruturações das instituições de saúde nos Estados Unidos ocasionaram efeitos no acompanhamento de pacientes usuários de opioides, bem como a disponibilidade de medicamentos em áreas remotas (HSER; MOONEY, 2020; WILSON et al., 2020), sendo destacada a necessária manutenção da assistência a esses pacientes no contexto da pandemia, dadas as possíveis repercussões nos quadros de depressão e ansiedade. Na área rural da Carolina do Norte, foram adotadas estratégias para atendimento desses pacientes, com redução de consultas presenciais pelas equipes - mantidas apenas para gestantes e pacientes com alta dependência - e substituição por teleconsultas; garantia da prescrição ou manutenção da receita dos medicamentos; suspensão das visitas para coleta de amostras para análise de drogas em casos de baixa e moderada dependência química; e revisão de protocolos de visita para os pacientes com alta dependência. (WILSON; RAMAGE, M.; FAGAN, 2020)

Mesmo após a superação da fase de maior contágio por COVID-19, os impactos negativos da interrupção ou redução das ações desenvolvidas no âmbito da APS deverão permanecer ou poderão ser ainda maiores. Os serviços de imunização infantil poderão ser afetados pela COVID-19, haja vista as recomendações da Organização Mundial da Saúde (OMS) para que os países avaliem a possibilidade de adiamento de campanhas de vacinação em massa. (WHO, 2020a) Em muitos países, as campanhas de vacinação necessitam do pleno funcionamento dos serviços primários para que as vacinas possam ser ofertadas à população. Nesse cenário, a situação é ainda mais grave nos países africanos com elevados indicadores de morbimortalidade por doenças imunopreviníveis. (ADAMU et al., 2020) Uma das consequências indiretas de outras epidemias no continente africano, como a de Ebola, foi a redução na utilização de 
serviços de saúde (WILHELM; HELLERINGER, 2019) acompanhada por múltiplas epidemias de sarampo. (SUK et al., 2016) No caso da COVID-19, um estudo realizado em comunidades de Serra Leoa mostrou redução de 50 a $80 \%$ na vacinação em crianças menores de cinco anos, comparando os meses de março e abril de 2019 e 2020. (BUONSENSO et al., 2020) Um estudo que estimou a relação risco-benefício, em 54 países africanos, comparando as mortes evitadas pela manutenção da imunização infantil de rotina com o excesso de mortes de COVID-19 associadas a visitas a clínicas de vacinação, concluiu que o benefício dos programas de vacinação infantil de rotina em todos os países foi maior do que o risco de óbitos por COVID-19 que possam porventura ocorrer devido a contaminações durante as visitas às unidades de saúde. (ABBAS et al., 2020)

Além da vacinação, os efeitos indiretos da pandemia de COVID-19 também poderão ser observados em outros indicadores de saúde materno-infantil, a exemplo do ocorreu durante a epidemia de Ebola na África, onde a interrupção na utilização de serviços de APS esteve associada à redução da cobertura da atenção pré-natal, das ações de planejamento familiar, ocorrência de partos hospitalares e consultas de puerpério (SOCHAS; CHANNON; NAM, 2017), possivelmente motivada pelo medo do vírus, escassez de recursos e alterações no funcionamento desses serviços. (ELSTON et al., 2016)

Em médio e longo prazo, as repercussões da redução do número de visitas aos serviços de APS poderão ser observadas no aumento de internações e de óbitos por doenças crônicas, afetando especialmente a população mais vulnerável e ampliando as inequidades em saúde. (MODESTI et al., 2020) Dessa forma, os esforços para o fortalecimento da APS devem ser mantidos e ampliados, garantindo a equidade do acesso seguro aos cuidados primários de saúde e aos demais níveis do sistema, incluindo mecanismos de participação social e os recursos comunitários na implementação das transformações nos sistemas de saúde e 
para incentivar novas formas de cuidar e promover a saúde da população.

Quadro 1 - Síntese das medidas adotadas nas experiências internacionais de reorganização da APS, 2020

\begin{tabular}{|c|c|c|}
\hline $\begin{array}{l}\text { Medida } \\
\text { adotada }\end{array}$ & País/Cidade (referência) & Descrição \\
\hline \multirow{4}{*}{  } & $\begin{array}{l}\text { Taiwan (CHANG; CHIU, } \\
\text { 2020); Inglaterra (MAJEED, } \\
\text { MAILIE; BINDMAN, 2020) }\end{array}$ & $\begin{array}{l}\text { Definição de unidades para atenção } \\
\text { para sintomáticos respiratórios / casos } \\
\text { suspeitos de COVID-19 e fluxo } \\
\text { de encaminhamento para outros } \\
\text { pontos de atenção. }\end{array}$ \\
\hline & $\begin{array}{c}\text { Malasia } \\
\text { (AMBIGAPATHY et al., 2020); } \\
\text { Reino Unido } \\
\text { (RAZAl et al., 2020) }\end{array}$ & $\begin{array}{c}\text { Sinalização na entrada das UBS } \\
\text { com solicitação para informar } \\
\text { a existência de sintomas respiratórios } \\
\text { na recepção ou triagem. }\end{array}$ \\
\hline & $\begin{array}{c}\text { Hong Kong } \\
\text { (CHAN et al., 2020); } \\
\text { Xangai, } \\
\text { (ZHONGQING, 2020); } \\
\text { Malásia } \\
\text { (AMBIGAPATHY et al., 2020). }\end{array}$ & $\begin{array}{l}\text { Entrada única de acesso nas unidades } \\
\text { de saúde, com aferição de temperatura. }\end{array}$ \\
\hline & $\begin{array}{c}\text { Espanha } \\
\text { (MERINO-NAVARRO; } \\
\text { DÍAZ-PERIÁNEZ, 2020). }\end{array}$ & $\begin{array}{l}\text { Instalação de sala pediátrica isolada } \\
\text { dos demais pacientes. }\end{array}$ \\
\hline
\end{tabular}




\begin{tabular}{|c|c|c|}
\hline $\begin{array}{r}\text { Medida } \\
\text { adotada }\end{array}$ & País/Cidade (referência) & Descrição \\
\hline \multirow{4}{*}{ 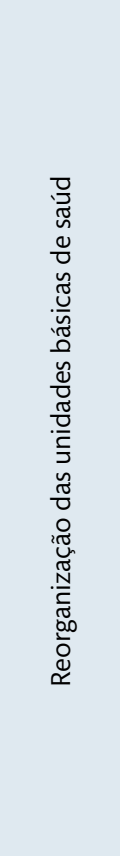 } & $\begin{array}{c}\text { Reino Unido } \\
\text { (RAZAl et al., 2020) }\end{array}$ & $\begin{array}{l}\text { Segregação de casos suspeitos através } \\
\text { da distinção de horários de atendimento } \\
\text { ou entradas separadas. }\end{array}$ \\
\hline & $\begin{array}{l}\text { Hong Kong } \\
\text { (CHAN et al., 2020); } \\
\text { Reino Unido } \\
\text { (RAZAl et al., 2020;) }\end{array}$ & $\begin{array}{l}\text { Uso de máscara cirúrgica e desinfecção } \\
\text { das mãos com álcool pelos pacientes } \\
\text { para acesso às UBS. }\end{array}$ \\
\hline & $\begin{array}{c}\text { Malasia } \\
\text { (AMBIGAPATHY et al., 2020) } \\
\text { Hong Kong } \\
\text { (CHAN et al., 2020); } \\
\text { Reino Unido } \\
\text { (RAZAl et al., 2020) }\end{array}$ & $\begin{array}{l}\text { Organização de área de espera especial } \\
\text { para sintomáticos respiratórios, com } \\
\text { ventilação e distanciamento físico } \\
\text { (1 a } 2 \text { metros). }\end{array}$ \\
\hline & $\begin{array}{c}\text { Reino Unido } \\
\text { (RAZAl et al., 2020) }\end{array}$ & $\begin{array}{l}\text { Suspensão do uso de sanitários comuns } \\
\text { por sintomáticos, e instalação sanitária } \\
\text { exclusiva, preferencialmente perto } \\
\text { da sala de isolamento. }\end{array}$ \\
\hline \multirow{2}{*}{ 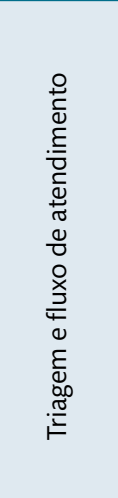 } & $\begin{array}{c}\text { Hong Kong } \\
\text { (CHAN et al., 2020; } \\
\text { Xangai (ZHONGQING, 2020) }\end{array}$ & $\begin{array}{l}\text { Triagem para investigação } \\
\text { epidemiológica e informações sobre } \\
\text { sintomas da doença e histórico } \\
\text { de viagens, especialmente no início } \\
\text { da pandemia. }\end{array}$ \\
\hline & $\begin{array}{c}\text { Hong Kong } \\
\text { (CHAN et al., 2020) }\end{array}$ & $\begin{array}{l}\text { Consulta de enfermagem com checklist } \\
\text { (Febre-Viagem-Ocupação-Contato- } \\
\text { Agrupamento) para identificação } \\
\text { de problemas respiratórios graves } \\
\text { e consultas médicas, com segunda } \\
\text { triagem para decisão sobre a } \\
\text { necessidade de internação. }\end{array}$ \\
\hline
\end{tabular}




\begin{tabular}{|c|c|c|}
\hline $\begin{array}{l}\text { Medida } \\
\text { adotada }\end{array}$ & País/Cidade (referência) & Descrição \\
\hline \multirow{2}{*}{ 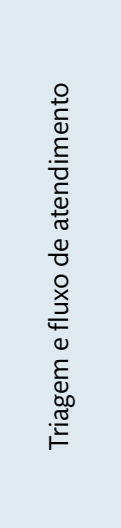 } & $\begin{array}{c}\text { Hong Kong } \\
\text { (CHAN et al., 2020); } \\
\text { Xangai } \\
\text { (ZHONGQING, 2020); } \\
\text { Reino Unido - } \\
\text { (GREENHALGH; } \\
\text { KOH; CAR, 2020). }\end{array}$ & $\begin{array}{c}\text { Sistemas de pré-agendamento } \\
\text { ou triagem prévia de pacientes } \\
\text { on-line ou telefone. }\end{array}$ \\
\hline & $\begin{array}{c}\text { Reino Unido } \\
\text { (RAZAl et al., 2020; } \\
\text { Malásia } \\
\text { (AMBIGAPATHY et al., 2020) }\end{array}$ & $\begin{array}{l}\text { Encaminhamento de casos graves } \\
\text { para demais pontos de atenção, com } \\
\text { uso preferencial de transporte próprio } \\
\text { da rede de saúde. }\end{array}$ \\
\hline 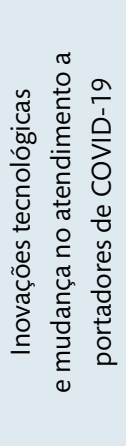 & $\begin{array}{c}\text { Reino Unido } \\
\text { (RAZAI et al., 2020; } \\
\text { GREENHALGH; KOH; } \\
\text { CAR, 2020; MARSHALL } \\
\text { et al., 2020); } \\
\text { Itália (FIORINO et al., 2020; } \\
\text { BRESSY; ZINGARELLI, 2020); } \\
\text { EUA (GRANGE; NEIL; } \\
\text { STOFFEL, 2020); } \\
\text { Austrália (ANDRIKOPOULOS; } \\
\text { JOHNSON, 2020) }\end{array}$ & $\begin{array}{l}\text { Substituição de consultas presenciais } \\
\text { por teleconsultas via chamada telefônica, } \\
\text { de vídeo ou outras tecnologias. }\end{array}$ \\
\hline
\end{tabular}




\begin{tabular}{|c|c|c|}
\hline $\begin{array}{l}\text { Medida } \\
\text { adotada }\end{array}$ & País/Cidade (referência) & Descrição \\
\hline \multirow{4}{*}{  } & $\begin{array}{c}\text { Reino Unido (GREENHALGH; } \\
\mathrm{KOH} \text { e CAR, 2020) }\end{array}$ & $\begin{array}{l}\text { Protocolos para realização } \\
\text { do teleatendimento (gerenciamento por } \\
\text { telefone para informações gerais sobre } \\
\text { COVID-19 ou casos leves e chamada } \\
\text { de vídeo para pacientes com histórico } \\
\text { de comorbidades ou pacientes com } \\
\text { sintomas moderados/severos); } \\
\text { e de orientações aos profissionais } \\
\text { sobre a condução da teleconsulta, } \\
\text { realização de exame físico } \\
\text { remotamente, notificação e } \\
\text { encaminhamentos, conforme grau de } \\
\text { manifestação da doença. }\end{array}$ \\
\hline & $\begin{array}{l}\text { Inglaterra (MAJEDD; MAILE; } \\
\text { BINDMAN, 2020) }\end{array}$ & $\begin{array}{l}\text { Informatização completa dos sistemas } \\
\text { como: registro médico eletrônico, } \\
\text { marcação de consultas on-line; } \\
\text { prescrições e visualização dos registros } \\
\text { médicos. }\end{array}$ \\
\hline & $\begin{array}{c}\text { Espanha (MARTÍNEZ-RIERA; } \\
\text { GRAS-NIETO, 2020). }\end{array}$ & $\begin{array}{l}\text { Visita domiciliar restritas a casos } \\
\text { específicos e substituídas teleconsultas. }\end{array}$ \\
\hline & $\begin{array}{l}\text { França (CHAMBOREDON; } \\
\text { ROMAN; COLSON, 2020) }\end{array}$ & $\begin{array}{l}\text { Serviço de telecare, conduzido } \\
\text { por enfermeiras de APS, para o manejo } \\
\text { clínico do paciente com } \\
\text { COVID-19, segundo critérios } \\
\text { estabelecidos, incluindo } \\
\text { o domínio das ferramentas } \\
\text { de telemonitoramento, } \\
\text { para orientações e suporte } \\
\text { às prescrições médicas. Realização } \\
\text { de visitas quando não era possível } \\
\text { o uso de ferramentas on-line, com } \\
\text { medidas de proteção aos profissionais. }\end{array}$ \\
\hline
\end{tabular}




\begin{tabular}{|c|c|c|}
\hline $\begin{array}{l}\text { Medida } \\
\text { adotada }\end{array}$ & País/Cidade (referência) & Descrição \\
\hline \multirow[t]{2}{*}{ 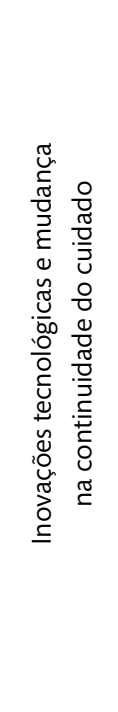 } & $\begin{array}{l}\text { EUA (WILSON; RAMAGE; } \\
\text { FAGAN 2020; HSER; } \\
\text { MOONEY, 2020; DEWAR, } \\
\text { et al., 2020; OLAYIWOLA } \\
\text { et al., 2020); } \\
\text { Suíça (BERAN et al., 2020); } \\
\text { Reino Unido (TRETHEWEY, } \\
\text { BECK; SYMONDS, 2020); } \\
\text { MEDICINE, 2020); } \\
\text { Austrália (KIDD, 2020); } \\
\text { Bélgica (VERHOEVEN } \\
\text { et al., 2020) }\end{array}$ & $\begin{array}{c}\text { Realização de teleconsulta } \\
\text { (chamada telefônica ou de vídeo): } \\
\text { idosos, pacientes com uso de opioides, } \\
\text { pessoas com doenças crônicas, } \\
\text { indígenas e população geral. }\end{array}$ \\
\hline & $\begin{array}{l}\text { EUA (OLAYIWOLA et al., } \\
\qquad 2020)\end{array}$ & $\begin{array}{l}\text { Telemonitoramento para } \\
\text { acompanhamento de bem-estar, de } \\
\text { saúde mental e aconselhamento sobre } \\
\text { estilo de vida. }\end{array}$ \\
\hline \multirow{2}{*}{ 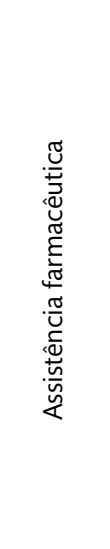 } & $\begin{array}{c}\text { Genebra } \\
\text { (BERAN et al., 2020); } \\
\text { África do Sul } \\
\text { (BREY et al., 2020); } \\
\text { Espanha (MARGUSINO- } \\
\text { FRAMIÑÁN et al., 2020); } \\
\text { Austrália (ANDRIKOPOULOS; } \\
\text { JOHNSON, 2020) }\end{array}$ & $\begin{array}{c}\text { Garantia de dispensação } \\
\text { de medicamentos ou entrega domiciliar. }\end{array}$ \\
\hline & $\begin{array}{l}\text { EUA (WILSON; RAMAGE; } \\
\text { FAGAN 2020); } \\
\text { Bélgica (VERHOEVEN et al., } \\
\text { 2020) }\end{array}$ & $\begin{array}{l}\text { Atualização de receitas para dispensa } \\
\text { de medicamento sem necessidade de } \\
\text { consulta com os usuários. }\end{array}$ \\
\hline
\end{tabular}

Fonte: elaborado pelos autores. 


\section{Experiências municipais de reorganização da APS em curso no Brasil}

O relato de experiências brasileiras publicado durante os primeiros meses da pandemia, sistematizado no Quadro 2, indicou o papel relevante das equipes de APS na atenção à COVID-19 e na integração com os demais pontos de atenção do SUS em municípios que apresentavam elevada cobertura populacional da Estratégia Saúde da Família (ESF) e que organizavam seu sistema de saúde com foco na APS. (FERNANDEZ et al., 2020; GUIMARÃES et al., 2020; RIBEIRO et al., 2020)

As equipes locais têm atuado na identificação, monitoramento clínico dos casos de COVID-19, rastreamento e monitoramento dos contatos. Os profissionais da APS têm assumido um papel importante na comunicação das orientações (CARDONA JÚNIOR; ANDRADE; CALDAS, 2020) para o isolamento dos casos e quarentena dos contatos, atuando no estímulo à adesão ao distanciamento social, higienização frequente das mãos, e uso de máscaras faciais, com atuação dos Agentes Comunitários de Saúde (ACS) nos territórios. (VALE et al., 2020; FERNANDEZ et al., 2020; RIBEIRO et al., 2020) Ações de suporte social a grupos vulneráveis têm sido implementadas, a exemplo das comunidades das favelas, população de rua, idosos vivendo em instituições de longa permanência e povos tradicionais, de modo que possam aderir às medidas de controle (FERNANDEZ et al., 2020; GUIMARÃES et al., 2020), orientações para a obtenção do auxílio emergencial do governo federal (MENDONÇA et al., 2020) e criação de estratégias comunitárias de comunicação via protagonismo juvenil. (SILVA JUNIOR et al., 2020; LATGÉ; ARAÚJO; SILVA JUNIOR, 2020)

Para a reorganização da atenção aos casos de COVID-19, as experiências destacaram as adaptações do espaço físico das unidades, 
com a criação de dupla entrada e sala de espera exclusiva parausuários sintomáticos respiratórios (GUIMARÃES et al., 2020; RIBEIRO et al., 2020; SILVEIRA; ZONTA, 2020); triagem de suspeitos de COVID-19 na recepção das unidades (FERNANDEZ et al., 2020; SILVEIRA; ZONTA, 2020; MENDONÇA et al., 2020) e identificação de idosos sintomáticos respiratórios classificados segundo vulnerabilidade clínico-funcional e estratificação de risco para hipertensão arterial e diabetes mellitus via WhatsApp, chamada telefônica ou visita domiciliar. (BARRA et al., 2020)

Ainda que no início da pandemia tenha havido restrição importante na realização das ações de rotina nas unidades básicas, outro eixo de ação relevante das equipes tem sido a garantia da continuidade do cuidado aos usuários portadores de condições crônicas, em especial idosos por sua vulnerabilidade quanto à manifestação de casos graves de COVID-19 (BARRA et al., 2020; SILVEIRA; ZONZA, 2020; GUIMARÃES et al., 2020), crianças menores de dois anos, gestantes (RIBEIRO et al., 2020) e mulheres vítimas de violência. (FERNANDEZ et al., 2020) A garantia das ações de rotina a exemplo da vacinação, o controle da tuberculose, do Vírus da Imunodeficiência Humana (HIV), da Síndrome da Imunodeficiência Adquirida (AIDS) e o apoio aos usuários portadores de sofrimento mental - é uma preocupação mencionada na maioria das experiências assinaladas.

As ações, sejam aquelas de atenção aos casos de COVID-19, sejam as destinadas à continuidade do cuidado aos usuários acompanhados pelas equipes têm se valido de ferramentas de atendimento remoto, com vistas à redução da circulação dos usuários vinculados às unidades básicas nos territórios. Telemonitoramento, teleconsulta, teleatendimento e teleagendamento via aplicativos disponíveis e registro em prontuários eletrônicos têm sido reforçados ou incorporados ao processo de trabalho das equipes como pode 
ser destacado nas experiências de Belo Horizonte, Florianópolis, Nova Lima, Canaã dos Carajás, Vitória. (GUIMARÃES et al., 2020; FERNANDEZ et al., 2020; RODRIGUES et al., 2020; SILVEIRA; ZONTA, 2020; VALE et al., 2020) Em alguns casos, essas ferramentas têm sido utilizadas por estudantes de Medicina e por residentes de Medicina de Família e Comunidade e de Enfermagem, que têm atuado na linha de frente do atendimento nas UBS. (SANTOS; FRANÇA; SANTOS, 2020; SILVEIRA et al., 2020)

Acerca da visita domiciliar, uma importante ferramenta do processo de trabalho dos ACS, a recomendação tem sido de adaptar a sua realização no espaço fora do domicílio - visita peridomiciliar -, em situações em que o usuário não tenha condição de receber o atendimento remoto ou por quadro clínico que exija o atendimento domiciliar. (RIBEIRO et al., 2020; VALE et al., 2020) O conhecimento existente sobre a população das áreas de abrangência, como usuários idosos portadores de condições crônicas classificados por estratificação de risco, tem orientado o planejamento das ações de cuidado rotineiro associadas à priorização desse grupo, seus familiares e cuidadores no que diz respeito ao controle da pandemia com diversos formatos de comunicação segundo as possibilidades dos usuários, de modo remoto ou por via presencial em visitas domiciliares. (BARRA et al., 2020)

As experiências municipais exitosas no enfrentamento da pandemia da COVID-19 estavam sustentadas, na maioria dos relatos, em reorganização dos processos de trabalho das equipes o que pode tornar a crise numa janela de oportunidade para fortalecer a APS no Brasil. A tão desejada integração entre ações de atenção e vigilância, sob a lógica do território-processo que determina os modos de viver e, consequentemente, os modos de adoecer e proteger a saúde da população, pode encontrar condições para seu estímulo e permanência nos serviços. 
Quadro 2 - Síntese de experiências municipais no enfrentamento da COVID-19, Brasil, 2020

\begin{tabular}{|c|c|c|}
\hline $\begin{array}{l}\text { Medida } \\
\text { adotada }\end{array}$ & Cidade (referência) & Descrição \\
\hline \multirow{2}{*}{ 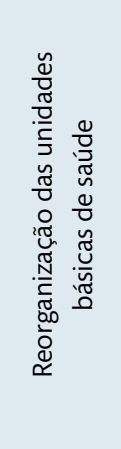 } & $\begin{array}{l}\text { Sobral (RIBEIRO et al., 2020); } \\
\text { Belo Horizonte } \\
\text { (GUIMARÃES et al., 2020); } \\
\text { Florianópolis } \\
\text { (SILVEIRA; ZONTA, 2020) }\end{array}$ & $\begin{array}{l}\text { Segregação de pacientes com suspeita de } \\
\text { COVID-19 através de entradas separadas. }\end{array}$ \\
\hline & $\begin{array}{l}\text { Nova Lima } \\
\text { (FERNANDEZ et al., 2020); } \\
\text { Sobral (RIBEIRO et al., 2020) }\end{array}$ & $\begin{array}{l}\text { Organização de área de espera } \\
\text { especial para pacientes } \\
\text { com sintomas respiratórios. }\end{array}$ \\
\hline \multirow{2}{*}{ 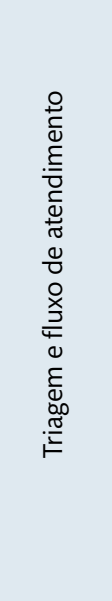 } & $\begin{array}{c}\text { Florianópolis } \\
\text { (SILVEIRA; ZONTA, 2020); } \\
\text { Porto Alegre } \\
\text { (MENDONÇA et al., 2020); } \\
\text { Nova Lima } \\
\text { (FERNANDEZ et al., 2020) }\end{array}$ & $\begin{array}{c}\text { Triagem na recepção por fornecimento } \\
\text { de informações pelo usuário sobre } \\
\text { sintomas da doença a profissional da } \\
\text { unidade. }\end{array}$ \\
\hline & $\begin{array}{c}\text { Uberlândia } \\
\text { (BARRA et al., 2020) }\end{array}$ & $\begin{array}{l}\text { Triagem prévia de idosos sintomáticos } \\
\text { respiratórios classificados segundo } \\
\text { vulnerabilidade clínico-funcional e } \\
\text { estratificação de risco - hipertensão } \\
\text { arterial e diabetes mellitus - via } \\
\text { WhatsApp, chamada telefônica } \\
\text { ou visita domiciliar. }\end{array}$ \\
\hline
\end{tabular}




\begin{tabular}{|c|c|c|}
\hline $\begin{array}{l}\text { Medida } \\
\text { adotada }\end{array}$ & Cidade (referência) & Descrição \\
\hline \multirow{4}{*}{ 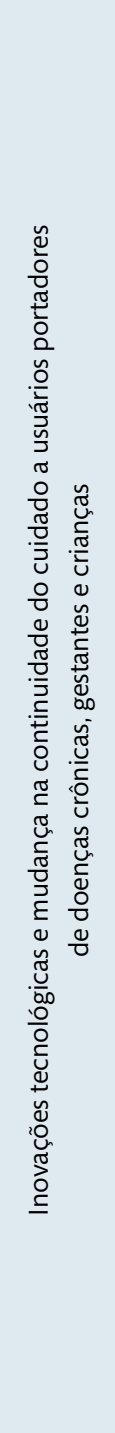 } & $\begin{array}{c}\text { Canaã dos Carajás } \\
\text { (VALE et al., 2020); } \\
\text { Florianópolis } \\
\text { (SILVEIRA e ZONTA, 2020); } \\
\text { Porto Alegre } \\
\text { (MENDONÇA et al., 2020); } \\
\text { Nova Lima } \\
\text { (FERNANDEZ et al., 2020); } \\
\text { Sobral (RIBEIRO et al., 2020), } \\
\text { Salvador (SANTOS, FRANÇA; } \\
\text { SANTOS, 2020); } \\
\text { Belo Horizonte } \\
\text { (GUIMARÃES et al., 2020); } \\
\text { Uberlândia } \\
\text { (BARRA et al., 2020) }\end{array}$ & $\begin{array}{c}\text { Substituição de consultas presenciais } \\
\text { por teleconsultas via chamada telefônica, } \\
\text { de vídeo ou outras tecnologias. }\end{array}$ \\
\hline & $\begin{array}{c}\text { Belo Horizonte } \\
\text { (GUIMARÃES et al., 2020) }\end{array}$ & $\begin{array}{l}\text { Criação de programa } \\
\text { para monitoramento de usuários } \\
\text { portadores de condições crônicas. }\end{array}$ \\
\hline & $\begin{array}{c}\text { Florianópolis } \\
\text { (SILVEIRA; ZONTA, 2020) }\end{array}$ & $\begin{array}{l}\text { Busca ativa telefônica ou através de } \\
\text { WhatsApp de usuários em situações } \\
\text { clínicas de maior risco ou vulnerabilidade } \\
\text { - gestantes de mais risco, usuárias para } \\
\text { primeira consulta de puericultura, } \\
\text { pacientes crônicos já conhecidos } \\
\text { das equipes, usuários hipertensos ou } \\
\text { diabéticos descompensados. }\end{array}$ \\
\hline & Sobral (RIBEIRO et al., 2020) & $\begin{array}{l}\text { Organização do atendimento à gestante } \\
\text { de baixo risco mediante agendamento } \\
\text { para reduzir risco de contágio nas UBS } \\
\text { e monitoramento remoto. Teleconsultoria } \\
\text { com obstetra para gestantes de alto risco. } \\
\text { Realização de ultrassonografia portátil } \\
\text { nas UBS. Manutenção da imunização } \\
\text { de rotina nas unidades. Realização de } \\
\text { campanha contra influenza em domicílio. }\end{array}$ \\
\hline
\end{tabular}




\begin{tabular}{|c|c|c|}
\hline $\begin{array}{l}\text { Medida } \\
\text { adotada }\end{array}$ & Cidade (referência) & Descrição \\
\hline \multirow{2}{*}{ 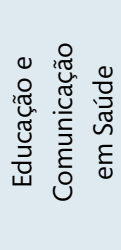 } & $\begin{array}{c}\text { Petrolina } \\
\text { (CARDONA JÚNIOR; } \\
\text { ANDRADE; CALDAS, 2020) }\end{array}$ & $\begin{array}{c}\text { Rádio comunitária e mensagens } \\
\text { por aplicativo (WhatsApp) } \\
\text { para usuários da zona rural. }\end{array}$ \\
\hline & $\begin{array}{c}\text { Florianópolis } \\
\text { (SILVEIRA; ZONTA, 2020) }\end{array}$ & $\begin{array}{c}\text { Divulgação de informações e combate } \\
\text { a notícias falsas via WhatsApp de cada } \\
\text { equipe de APS. }\end{array}$ \\
\hline 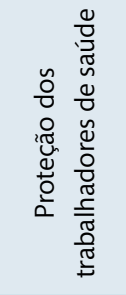 & $\begin{array}{l}\text { Canaã dos Carajás } \\
\text { (VALE et al., 2020) }\end{array}$ & $\begin{array}{c}\text { Monitoramento diário de profissionais de } \\
\text { saúde para identificação de sintomáticos } \\
\text { respiratórios }\end{array}$ \\
\hline \multirow{3}{*}{ 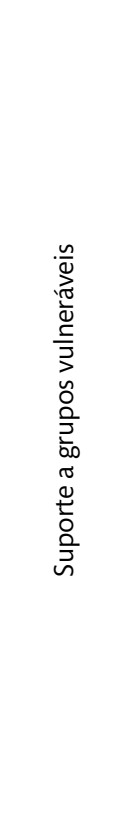 } & $\begin{array}{c}\text { Belo Horizonte } \\
\text { (GUIMARÃES et al., 2020) }\end{array}$ & $\begin{array}{l}\text { Atendimento específico à população } \\
\text { de rua e aos idosos que vivem } \\
\text { em instituições de longa permanência } \\
\text { ema articulação com outras secretarias } \\
\text { da prefeitura e com apoio } \\
\text { da Universidade Federal } \\
\text { de Minas Gerais (UFMG). }\end{array}$ \\
\hline & $\begin{array}{l}\text { Niterói (LATGÉ; ARAÚJO } \\
\text { SILVA JUNIOR, 2020) }\end{array}$ & $\begin{array}{l}\text { Distribuição de máscaras em tecido } \\
\text { para a população em área de vilas } \\
\text { e favelas pelos ACS e Agentes } \\
\text { de Combate a Endemias, como } \\
\text { oportunidade de uma ação de vigilância } \\
\text { e educação em saúde no momento } \\
\text { de cada entrega. }\end{array}$ \\
\hline & $\begin{array}{c}\text { Porto Alegre (MENDONÇA } \\
\text { et al., 2020) }\end{array}$ & $\begin{array}{l}\text { Serviço social e ACS identificam e apoiam } \\
\text { os potenciais beneficiários do programa } \\
\text { de renda emergencial para trabalhadores } \\
\text { não protegidos por vínculos formais } \\
\text { de trabalhador e beneficiários } \\
\text { do Bolsa Família. }\end{array}$ \\
\hline
\end{tabular}




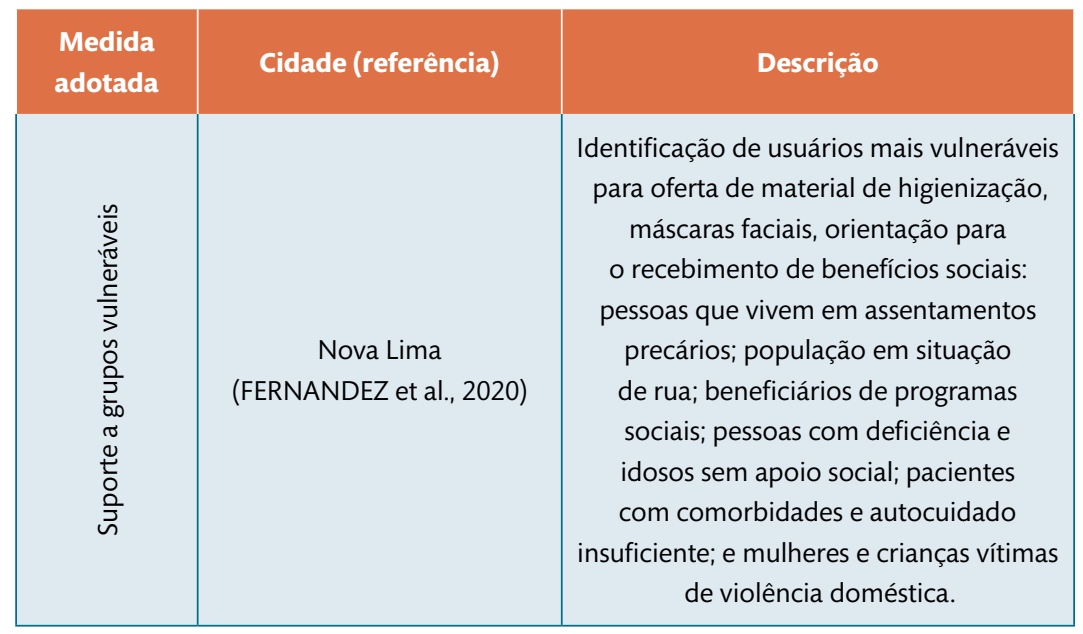

Fonte: elaborado pelos autores.

\section{Reflexões sobre as experiências de reorganização da APS: o que podemos aprender?}

As experiências nacionais e internacionais analisadas retrataram alguns cenários da primeira onda da expansão de uma pandemia por um agente infeccioso desconhecido. Ao tempo em que ilustraram a grande capacidade de reorganização dos serviços de APS em diversificados contextos socioeconômicos e de organização dos sistemas nacionais de saúde, também delinearam desafios atuais e futuros, que precisarão ser urgentemente enfrentados para evitar impactos catastróficos sobre a saúde da população mundial. Para além dos milhares de casos e óbitos de COVID-19, os impactos já identificados da interrupção ou redução do funcionamento dos serviços de saúde poderão ser ampliados, causando 
nefastos retrocessos na situação de morbimortalidade de diversos problemas de que já estavam sob controle em muitos países e agravando as situações de vulnerabilidade dos países mais pobres, aumentando as desigualdades sociais existentes.

No âmbito da APS, a pandemia impactou não apenas as ações assistenciais desenvolvidas no interior das unidades de saúde, como também atividades basilares que conferem o seu caráter territorial e comunitário, como as visitas domiciliares e as ações, desenvolvidas pelas equipes em suas áreas de abrangência, de promoção da saúde, participação social e prevenção de doenças e agravos. Por outro lado, mesmo que pontuais, algumas experiências nacionais apontaram alternativas de articulação com lideranças comunitárias e o movimento social, para detecção de casos e implementação de medidas de controle e de apoio social e para atuação do ACS, com a renovação dos modos de interação com as famílias no espaço peridomiciliar, que levantaram necessidades de capacitação e proteção adequada dos ACS para maior circulação nos territórios. Experiências internacionais, como no Reino Unido, destacaram inovações do processo de trabalho dos médicos de APS, que apontam para um "reequilíbrio dos modelos psicossocial, biomédico e de saúde pública da clínica geral”, evidenciado no maior envolvimento desses profissionais em atividades de planejamento de saúde da população, redesenho de trajetórias clínicas, priorização de recursos segundo necessidades, utilização de recursos comunitários e preparação para emergências. (MARSHALL et al., 2020)

O amplo espectro de ações que se somaram às atividades corriqueiras desenvolvidas pelas equipes de APS têm trazido enormes desafios e exigido, dadas as características peculiares da doença e de seu agente causador, uma grande mudança no modus operandi das equipes, cuja reorganização do processo de trabalho tem implicado na redistribuição de tarefas e atividades entre os membros 
das equipes, na reestruturação do espaço físico e fluxos de atendimento (CHAMBOREDO; RAMAN; COLSON, 2020; GREENHALGH; KOH; CAR, 2020; RAZAI et al., 2020) e na incorporação e utilização de TICs que têm apoiado o desenvolvimento de um vasto número de atividades na APS: educativas e de produção de informação, apoio social e vínculo com as comunidades (CARDONA JÚNIOR; ANDRADE; CALDAS, 2020; SILVEIRA; ZONTA, 2020), de vigilância epidemiológica (GREENHALGH; KOH; CAR, 2020), de monitoramento e atendimento aos pacientes. (CHAMBOREDON; RAMAN; COLSON, 2020; GREENHALGH; KOH; CAR, 2020)

Em todo mundo, a incorporação dessas tecnologias tem se mostrado como uma das principais estratégias inovadoras e tem contribuído para aliar as formas presenciais e remota nas atividades desenvolvidas no território, junto às famílias, e no cuidado individualizado dos usuários que são acompanhados pelos serviços de saúde. Como resposta rápida, viável e promissora no âmbito da APS para atenção aos pacientes de COVID-19 e para garantia do cuidado rotineiro à população, frente à condição de excepcionalidade decorrente da pandemia, suas vantagens na atenção aos usuários têm sido ressaltadas.

Nunca foi tão clara a importância da utilização das TICs como nesta pandemia para o acesso não apenas a serviços de saúde, como a toda sorte de serviços públicos e privados, como educação, cadastramento em benefícios sociais ou mesmo para o abastecimento doméstico com bens de primeira necessidade. Em muitos serviços públicos de saúde, como no caso do Brasil, a mudança foi drástica, passando de uma realidade em que toda interação com os usuários era presencial e era difícil realizar uma simples marcação de consulta pelo telefone, para a necessidade de ampla utilização dessas ferramentas.

Embora de inestimável valor, precisamos atentar para os riscos do fetiche da tecnologia, pois não se trata de uma panaceia 
que resolverá todos os problemas e tais ferramentas não estão disponíveis para todos, especialmente, para aqueles com maior vulnerabilidade socioeconômica ou que residem em áreas remotas, o que pode ampliar as desigualdades em saúde. Nas experiências analisadas, limitações para a sua implementação foram destacadas, especialmente, na África, em locais que não dispunham de sistemas e redes tecnológicas nas unidades de saúde ou de amplo acesso pelos profissionais, havendo necessidade de grandes investimentos para implantação desses serviços. (CHERSICH et al., 2020) Também foram apontados desafios na França, em áreas mais vulneráveis, com reduzido acesso à internet e menor o nível de alfabetização digital (JULIA et al., 2020) e na Itália, entre os idosos e indivíduos que possuíam dificuldades no manuseio de ferramentas digitais, comprometendo a realização das teleconsultas. (BRESSY; ZINGARELLI, 2020)

Além das desigualdades de acesso da população, é fundamental a qualificação dos serviços e profissionais de saúde, pois locais que já possuíam experiências prévias de implantação desses serviços demostraram-se mais facilidade e êxito na rápida utilização dessas estratégias. (DEWAR et al., 2020; OLAYIWOLA et al., 2020) Adicionalmente, o debate quanto ao uso desses recursos tecnológicos na atenção à saúde tem destacado questões de natureza ética, como a garantia à privacidade, anonimato e confidencialidade das informações do paciente (BRESSY; ZINGARELLI, 2020); da qualidade do atendimento, pelo menor número de informações captadas, especialmente sobre o exame físico, que podem comprometer a capacidade de diagnóstico (VERHOEVEN et al., 2020), especialmente nas chamadas telefônicas em comparação com chamadas de vídeo; as incertezas quanto às repercussões sobre os vínculos paciente-profissional e ao compartilhamento das decisões pelas equipes (MARSHALL et al., 2020); e fatores de natureza econômica, como a necessidade de regulamentação da cobertura dos 
procedimentos e de investimentos públicos na implementação dos sistemas para garantia da equidade do acesso para a população.

\section{Notas finais sobre a experiência brasileira: um modelo de sucesso ameaçado}

No Brasil, a crise sanitária deflagrada pela pandemia de COVID-19 evidenciou desafios que há muito vêm sendo enfrentados, como o desfinanciamento do SUS, aprofundado com a Emenda Constitucional $\mathrm{n}^{\circ} 95$, e aumento das iniquidades sociais em saúde. Diversas medidas do governo federal têm contribuído para descoordenação e ineficiência da resposta nacional à pandemia, instaurando uma crise política sem precedentes. Alguns exemplos podem ser citados, como: a tentativa de restringir o poder dos governadores e prefeitos em definir ações necessárias para combater o novo coronavírus, derrubada pelo Supremo Tribunal Federal (STF) em abril; o veto presidencial à obrigatoriedade do uso de máscara em instituições de ensino, comércio, e templos e para distribuição gratuita de materiais de higiene e limpeza para aldeias ou comunidades indígenas, derrubados pelo Congresso Nacional; e o atraso na liberação dos recursos emergenciais, alvo de inquérito do Ministério Público Federal (MPF) e auditoria do Tribunal de Contas da União (TCU), que identificou que apenas um terço das verbas havia sido executado até o mês de junho de 2020.

No âmbito da APS, medidas adotadas desde 2017, com a nova Política Nacional de Atenção Básica, representaram um grande retrocesso das conquistas alcançadas nas últimas três décadas na construção de uma política de APS, com impactos nefastos à saúde da população, destacando-se: a nova modalidade de financiamento, com o fim do Piso de Atenção Básica (PAB) fixo e variável; extinção da prioridade para ESF e de incentivos fundamentais 
para seu fortalecimento, como os Núcleos Ampliados de Saúde da Família (NASF); redução do número de ACS e da carga horária dos profissionais; e o fim do Programa Mais Médicos. (REDE DE PESQUISA EM ATENÇÃO PRIMÁRIA À SAÚDE DA ABRASCO, 2018)

$O$ surgimento da pandemia nessa conjuntura de desmonte da exitosa experiência brasileira, aliado a uma preocupação predominante com a preparação da capacidade hospitalar para o atendimento de casos graves, resultou, até o momento, em intervenções desarticuladas das esferas de gestão federal, estadual e municipal do SUS, assim como dos níveis de atenção e da vigilância em saúde, comprometendo, em especial a capacidade de resposta da APS, que ainda está limitada a algumas experiências estaduais e municipais.

Inúmeros autores têm reconhecido que o modelo brasileiro de APS, a ESF, responde com elevado grau de adequação ao complexo desafio de enfrentamento da epidemia, posto que apresenta características e atributos calcados no vínculo com a população e na ação comunitária (COELHO et al., 2020; MEDINA et al., 2020; NEDEL, 2020; VITÓRIA; CAMPOS, 2020): a presença do ACS no território, o conhecimento dos profissionais de saúde sobre as condições gerais de vida e de saúde das populações adstritas, a permanência regular das equipes e sua articulação com instituições sociais e organizações comunitárias. O grande esforço de construção de uma APS acessível, robusta e de qualidade nos 30 anos de construção do SUS produziu resultados alentadores com melhorias em termos de organização dos serviços e de indicadores de saúde no Brasil. As conquistas obtidas nesse processo, hoje fortemente ameaçadas, fizeram com que florescessem no Brasil experiências exitosas de enfrentamento da epidemia, diante de um quadro desolador de descoordenação e desfinanciamento global do SUS no país. É interessante observar que tanto a literatura internacional (HAINES et al., 2020) quanto organismos 
internacionais (WHO, 2020b) colocam em perspectiva o enfrentamento global da pandemia, sinalizando modos de operar que são caros ao modelo de APS brasileira. Cabe-nos, portanto, ao buscar aprender com as experiências internacionais e nacionais, reconhecer que é necessário defender e recuperar o legado que trouxemos até aqui.

Os desafios para garantir a atenção aos pacientes de COVID-19 e todo o elenco de ações e problemas de saúde na APS que não podem ser descontinuados são enormes, devendo ser prioridade governamental, com o devido aporte orçamentário da União. As principais ações são: readequar os espaços físicos e equipar as UBS para resguardar usuários, acompanhantes e profissionais, especialmente, em pequenos municípios, que padecem de deficiências estruturais e carência de equipamentos de telecomunicação e internet; proteger de forma adequada os profissionais de saúde para assegurar o cumprimento das normas de biossegurança, de acordo com o tipo de atividade ou procedimento realizado, através da disponibilização dos EPIs e capacitação para o uso seguro e adequado; educação permanente das equipes para o manejo clínico atualizado e vigilância em saúde oportuna; ampliar a capacidade de identificação de casos e suspeitos, de modo a corrigir a enorme subnotificação no Brasil, inaceitável em um contexto de relaxamento das medidas de controle; ampliar os procedimentos nas UBS, como leitos de observação e estabilização, o que inclui equipamentos e procedimentos que não eram rotineiramente utilizados em muitas UBS; garantir a referência dos casos que necessitam de atendimento hospitalar, através das centrais de regulação de transporte e leitos, um dos gargalos históricos para melhor resolubilidade dos serviços de saúde. E, por fim, mas não menos importante, é essencial que o governo federal assuma seu papel de coordenador das ações, ao lado dos estados e municípios tal como prevê a legislação do SUS, de modo a reduzir iniquidades 


\section{na oferta dos serviços e contribuir para a mitigação dos efeitos da pandemia sobre a vida de todos os brasileiros.}

\section{Referências}

ABBAS, K. et al. Routine childhood immunisation during the COVID-19 pandemic in Africa: a benefit: risk analysis of health benefits versus excess risk of SARS-COV-2 infection. The Lancet Global Health, [s. I.], v. 8, n. 10, p. 1264-1272, 2020.

ADAMU, A. A. et al. COVID-19 and routine childhood immunization in Africa: leveraging systems thinking and implementation science to improve immunization system performance. International Journal Of Infectious Diseases, Hamilton, v. 98, p. 161-165, 2020.

AMBIGAPATHY, S. et al. How should front-line general practitioners use personal protective equipment (PPE)? Malaysian Family Physician: the Official Journal of the Academy of Family Physicians of Malaysia, Kuala Lumpur, v. 15, n. 1, p. 2, 2020.

ANDRIKOPOULOS, S.; JOHNSON, G. The Australian response to the COVID-19 pandemic and diabetes - Lessons learned. Diabetes Research And Clinical Practice, Amsterdam, v. 165, p. 108246, 2020.

BADRFAM, R.; ZANDIFAR, A. Coronavirus disease 2019 in Iran: the need for more attention to primary health care. Public Health, London, v. 182, p. 187, 2020.

BARRA, R. P. et al. A importância da gestão correta da condição crônica na Atenção Primária à Saúde para o enfrentamento do Covid-19 em Uberlândia, Minas Gerais. APS em Revista, Rio de Janeiro, v. 2, n. 1, p. 38-43, 2020. DOI: https://doi. org/10.14295/aps.v2i1.64. Disponível em: https://apsemrevista.org/aps/article/ view/64. Acesso em: 22 ago. 2020.

BERAN, D. et al. Beyond the virus: ensuring continuity of care for people with diabetes during covid-19. Primary Care Diabetes, Kidlington, p. 1-2, 2020.

BHAUMIK, S. et al. Community health workers for pandemic response: a rapid evidence synthesis. British Medical Journal Global Health, London, v. 5, n. 6, p. 1-20, 2020. Disponível em: https://doi.org/10.1101/2020.04.28.20082586. Acesso em: 17 maio 2020. 
BRASIL. Ministério da Saúde. Secretaria de Atenção à Saúde. Secretaria de Vigilância em Saúde. Guia Política Nacional de Atenção Básica - módulo 1: integração atenção básica e vigilância em saúde. Brasília, DF: Ministério da Saúde, 2018. Disponível em: http://bvsms.saude.gov.br/bvs/publicacoes/guia_politica_ nacional_atencao_basica_integracao_atencao_basica_vigilancia_saude_modulo_1. pdf . Acesso em: 29 set. 2020.

BRESSY, S.; ZINGARELLI, E. M. Technological devices in Covid-19 primary care management: the Italian experience. Family Practice, Oxford, v. 37, n. 5, p. $725-726,2020$.

BREY, Z. et al. Home delivery of medication during Coronavirus disease 2019, Cape Town, South Africa. African Journal of Primary Health Care \& Family Medicine, Tygervalley, v. 12, n. 1, p. 4, 2020.

BUONSENSO, D. et al. Child Healthcare and Immunizations in Sub-Saharan Africa During the Covid-19 Pandemic. Frontiers in Pediatrics, Lausanne, v. 8, p. 517, 2020. Disponível em: https://doi.org/10.3389/fped.2020.00517. Acesso em: 24 set. 2020.

CARDONA JÚNIOR, A. H. dos S.; ANDRADE, C. W. de Q.; CALDAS, L. N. M. Educação em saúde: programa e canal de comunicação via WhatsApp da unidade básica de saúde do N6 para comunidade rural do sertão pernambucano. APS em Revista, Belo Horizonte, v. 2, n. 2, p. 137-141, 2020. DOI: https://doi.org/10.14295/ aps.v2i2.92. Disponível em: https://apsemrevista.org/aps/article/view/92. Acesso em: 22 ago. 2020.

CHAMBOREDON, P.; ROMAN, C.; COLSON, S. Covid-19 pandemic in France: health emergency experiences from the field. International Nursing Review, Oxford, v. 67, n. 3, p. 326-333, 2020.

CHAN, P. F. et al. Enhancing the triage and cohort of patients in public primary care clinics in response to the coronavirus disease 2019 (COVID-19) in Hong Kong: an experience from a hospital cluster. British Journal of General Practice, London, v. 4, n. 2, p. 1-5, 2020.

Chang, B. B. J.; Chiu, T. Y. Ready for a long fight against the COVID-19 outbreak: an innovative model of tiered primary health care in Taiwan. British Journal of General Practice Open, London, v. 4, n. 2, p. 1-3, 2020.

CHERSICH, M. F. et al. COVID-19 in Africa: care and protection for frontline healthcare workers. Globalization and Health, London, v. 16, n. 1, p. 1-6, 2020. 
COELHO, V. S. P. et al. Vale apostar na Atenção Primária à Saúde contra o Covid-19. Novos Estudos Cebrap, São Paulo, 2020. Disponível em: http://novosestudos. uol.com.br/vale-apostar-na-atencao-primaria-a-saude-contra-a-covid-19/. Acesso em: 28 mai 2020.

COVID-19 in Brazil: "So what?" The Lancet, Londron, v. 395, n. 10235, p. 1461, 2020. DOI: http://dx.doi.org/10.1016/S0140-6736(20)31095-3. Disponível em: https:// www.thelancet.com/journals/lancet/article/PIIS0140-6736(20)31095-3/fulltext. Acesso em: 22 set. 2020.

COVID-19 HERALDS a new era for chronic diseases in primary care. The Lancet Respiratory Medicine, Kidlington, v. 8, n. 7, p. 647, July 2020.

DAVID, N; MASH, R. Community-based screening and testing for Coronavirus in Cape Town, South Africa. African Journal of Primary Health Care \& Family Medicine, Tygervalley, v. 12, n. 1, p. 1-3, 2020.

DEWAR, S. et al. Uptake of Virtual Visits in A Geriatric Primary Care Clinic During the COVID -19 Pandemic. Journal of The American Geriatrics Society, Malden, v. 68, n. 7, p. 1392-1394, 2020.

DUNLOP, C. et al. The coronavirus outbreak: the central role of primary care in emergency preparedness and response. British Journal of General Practice Open, London, v. 4, n. 1, p. 1-3, 28 Jan. 2020.

ELSTON, J. W. T. et al. Impact of the Ebola outbreak on health systems and population health in Sierra Leone. Journal of Public Health, Oxford, v. 38, n. 4, p. $673-678,2016$.

FERNANDEZ, M. V. et al. Reorganizar para avançar: a experiência da Atenção Primária à Saúde de Nova Lima/MG no enfrentamento da pandemia da Covid-19. APS em Revista, Rio de Janeiro, v. 2, n. 2, p. 114-121, jun. 2020. DOI: https://doi. org/10.14295/aps.v2i2.84. Disponível em: https://apsemrevista.org/aps/article/ view/84. Acesso em: 22 ago. 2020.

FIORINO, G. et al. Clinician Education and Adoption of Preventive Measures for Covid-19: A Survey of a Convenience Sample of General Practitioners in Lombardy, Italy. Annals of Internal Medicine, Philadelphia, v. 173, n. 5, p. 405-407, 2020.

GARG, S. et al. Primary Health Care Facility Preparedness for Outpatient Service Provision during the Covid-19 Pandemic in India: Cross-Sectional Study. JMIR Public Health and Surveillance, Toronto, v. 6, n. 2, p. 19927, 2020. 
GILLIES, J. et al. The Wass report: moving forward 3 years on. British Journal of General Practice, London, v. 70, n. 694, p. 164-165, 2020.

GIOVANELLA, L. et al. Negacionismo, desdém e mortes: notas sobre a atuação criminosa do governo federal no enfrentamento da Covid-19. Saúde em Debate, Rio de Janeiro, 2020. No prelo.

GRANGE, E. S. et al. Responding to Covid-19: The UW medicine information technology services experience. Applied clinical informatics, Hölderlinstr, v. 11, n. 2, p. $265-275,2020$.

GRASSELLI, G. et al. Baseline characteristics and outcomes of 1591 patients infected with SARS-CoV-2 admitted to ICUs of the Lombardy Region, Italy. JAMA, Chicago, v. 323, n. 16, p. 1574-1581, 2020.

GREENHALGH, T.; KOH, G. C. H.; CAR, J. Covid-19: a remote assessment in primary care. The British Medical Journal, London, v. 368, 2020. DOI: https://doi. org/10.1136/bmj.m1182. Disponível em: https://www.bmj.com/content/368/bmj. m1182. Acesso em: 28 jul. 2020.

GUIMARÃES, F. et al. A organização da Atenção Primária à Saúde de Belo Horizonte no enfrentamento da Pandemia Covid 19: relato de experiência. APS em Revista, Belo Horizonte, v. 2, n. 2, p. 74-82, 2020. DOI: https://doi.org/10.14295/ aps.v2i2.128. Disponível em: https://apsemrevista.org/aps/article/view/128. Acesso em: 22 ago 2020.

HAINES, A. et al. National UK programme of community health workers for COVID-19 response. The Lancet, London, v. 395, n. 10231, p. 1173-1175, 2020.

HOLSTEIN, B. Coronavirus 101. The Journal for Nurse Practitioners, New York, v. 16, n. 6, p. 416-419, 2020.

HSER, Y. I; MOONEY, L. J. Integrating Telemedicine for Medication Treatment for Opioid Use Disorder in Rural Primary Care: Beyond the COVID Pandemic. The Journal of Rural Health, Oxford, 2020. Disponivel em: https://doi.org/10.1111/ jrh.12489. Acesso em: 29 ago 2020.

HUSTON, P. et al. Covid-19 and primary care in six countries. British Journal of General Practice Open, London, v. 4, n. 4, 2020. Disponível em: https://doi. org/10.3399/bjgpopen20X101128. Acesso em: 23 set. 2020.

JALY, I. et al. Redefining diabetic foot disease management service during COVID-19 pandemic. Diabetes \& Metabolic Syndrome: Clinical Research \& Reviews, Amsterdam, v. 14, n. 5, p. 833-838, 2020. 
JONES, D. et al. Impact of the Covid-19 pandemic on the symptomatic diagnosis of cancer: the view from primary care. The Lancet Oncology, London, v. 21, n. 6, p. $748-750,2020$.

JOY, M. et al. Reorganisation of primary care for older adults during Covid-19: a cross-sectional database study in the UK. British Journal of General Practice, London, v. 70, n. 697, p. 540-547, 2020.

JULIA, C. et al. Organizing community primary care in the age of Covid-19: challenges in disadvantaged areas. Lancet Public Health, Oxford, v. 5, n. 6, 2020. DOI: https://doi.org/10.1016/S2468-2667(20)30115-8. Disponível em: https:// www.thelancet.com/journals/lanpub/article/PIIS2468-2667(20)30115-8/fulltext. Acesso em: 10 set. 2020.

KIDD, M. R. Five principles for pandemic preparedness: lessons from the Australian Covid-19 primary care response. British Journal of General Practice, London, v. 70, n. 696, p. 316-317, 2020.

KRZNARIĆ, Z. et al. A simple remote nutritional screening tool and practical guidance for nutritional care in primary practice during the Covid-19 pandemic. Clinical Nutrition, Kidlington, v. 39, n. 7, p. 1983-1987, 2020.

LAM, L. T. M; CHUA, Y. X.; TAN, D. H. Y. Roles and challenges of primary care physicians facing a dual outbreak of Covid-19 and dengue in Singapore. Family Practice, Oxford, v. 37, n. 4, p. 578-579, 2020. Disponível em: https://doi. org/10.1093/fampra/cmaa047. Acesso em: 1 set. 2020.

LATGÉ, P. K.; ARAÚJO, D. N.; SILVA JUNIOR, A. G. da. Comunicação, educação e vigilância popular em saúde em tempos de Covid-19-a experiência das comunidades de Niterói, RJ. APS em Revista, Belo Horizonte, v. 2, n. 2, p. 122-127, jun. 2020. DOI: https://doi.org/10.14295/aps.v2i2.110. Disponível em: Acesso em: 22 ago. 2020.

MAJEED, A.; MAILE, E. J; BINDMAN, A. B. The primary care response to Covid-19 in England's National Health Service. Journal of the Royal Society of Medicine, London, v. 113, n. 6, p. 208-210, 2020.

MARGUSINO-FRAMIÑÁN, L. et al. Pharmaceutical care to hospital outpatients during the COVID-19 pandemic. Telepharmacy. Farmacia hospitalaria: organo oficial de expresion cientifica de la Sociedad Espanola de Farmacia Hospitalaria, Madrid, v. 44, n. 7, p. 61-65, 2020. 
MARSHALL, M. et al. Covid-19: a danger and an opportunity for the future of general practice. British Journal of General Practice, London, v. 70, n. 695, p. 270-271, 2020.

MARTÍNEZ-RIERA, J. R.; GRAS-NIETO, E. Atención domiciliaria y COVID-19. Antes, durante y después del estado de alarma. Enfermería Clínica, Madrid, Jan. 2020. DOI: 10.1016/j.enfcli.2020.05.003. Disponível em: https://doi.org/ 10.1016/j. enfcli.2020.05.003. Acesso em: 22 ago. 2020.

MASH, B. Primary care management of the coronavirus (Covid-19). South African Family Practice: Official Journal of the South African Academy of Family Practice/ primary Care, [s. I.], v. 62, n. 1, p. 5144-5144, 2020.

MEDINA, M. G. et al. Atenção primária à saúde em tempos de COVID-19: o que fazer?. Cadernos de Saúde Pública, Rio de Janeiro, v. 36, n. 8, p. 1-5, 2020.

MEDINA-POLO, J. et al. Benign prostatic hyperplasia management during Covid-19 pandemia. Archivos Espanoles de Urologia, Madrid, v. 73, n. 5, p. 405-412, 2020.

MENDONÇA, C. et al. Resposta assistencial de um serviço docente assistencial de APS à pandemia da Covid-19. APS em Revista, Belo Horizonte, v. 2, n. 1, p. 33-37, 2020. DOI: https://doi.org/10.14295/aps.v2i1.63. Disponível em: https:// apsemrevista.org/aps/article/view/63. Acesso em: 22 ago. 2020.

MERINO-NAVARRO, D.; DÍAZ-PERIÁNEZ, C. Prevention and treatment of Covid-19 in the pediatric population from the family and community perspective. Enfermería Clínica, Barcelona, 2020. DOI: https://doi.org/10.1016/j.enfcli.2020.05.005. Disponível em: https://www.sciencedirect.com/science/article/abs/pii/ S1130862120303016?via\%3Dihub. Acesso em: 29 jul. 2020.

MINUÉ-LORENZO, S. La pandemia Covid-19: lo que hemos aprendido hasta ahora desde España. APS em Revista, Belo Horizonte v. 2, n. 1, p. 28-32, 2020. Disponível em: https://apsemrevista.org/aps/article/view/66. Acesso em: 28 maio 2020.

MODESTI, P. A. et al. Indirect implications of COVID-19 prevention strategies on non-communicable diseases. BioMed Central Medicine, [s. I.], v. 18, n. 1, p. 1-16, 2020.

NACOTI, M. et al. At the Epicenter of the Covid-19 Pandemic and Humanitarian Crises in Italy: Changing Perspectives on Preparation and Mitigation. New England Journal of Medicine Catalyst, [s. I.], 2020. Disponível em: https://catalyst. nejm.org/doi/pdf/10.1056/CAT.20.0080. Acesso 29 set. 2020. 
NEDEL, F. B. Enfrentando a COVID-19: APS forte agora mais que nunca! APS em revista, Belo Horizonte, v. 2, n. 1, p. 11-16, 2020.

OLAYIWOLA, J. N. et al. Telehealth as a Bright Spot of the COVID-19 Pandemic: recommendations from the virtual frontlines. Jmir Public Health And Surveillance, Toronto, v. 6, n. 2, p. e19045, 2020.

RAZAI, M. S. et al. Coronavirus disease 2019 (covid-19): A guide for UK GPS. BMJ, Londron, v. 368, p. 1-5, 2020.

REDE DE PESQUISA EM ATENÇÃO PRIMÁRIA À SAÚDE DA ABRASCO.

Contribuição para uma agenda política estratégica para a Atenção Primária à Saúde no SUS. Saúde em Debate, Rio de janeiro, v. 42, set. 2018. Disponível em: http://dx.doi.org/10.1590/0103-11042018s128. Acesso em: 15 jun. 2020.

RIBEIRO, M. A. et al. (RE) Organização da Atenção Primária à Saúde para o enfrentamento da COVID-19: Experiência de Sobral-CE. APS em Revista, Belo Horizonte, v. 2, n. 2, p. 177-188, 2020. DOI: https://doi.org/10.14295/ aps.v2i2.125. Disponível em: https://apsemrevista.org/aps/article/view/125. Acesso em: 10 ago. 2020.

RODRIGUES, A. P. et al. Telemonitoramento como estratégia de cuidado longitudinal a grupos prioritários em tempos da COVID-19: uma experiência na atenção primária à saúde do município de Vitória-ES. APS em Revista, Belo Horizonte, v. 2, n. 2, p. 189-196, 2020. DOI: https://doi.org/10.14295/ aps.v2i2.100. Disponível em: https://apsemrevista.org/aps/article/view/100. Acesso em: 25 jul. 2020.

ROYAL COLLEGE OF GENERAL PRACTITIONERS RESEARCH; SURVEILLANCE CENTRE. RCGP RSC Workload Observatory. 2020. Disponível em: https://clininf.eu/ index.php/rcgprscworkloadobservatory/. Acesso em: 14 set. 2020.

SANTOS, A. B. S. dos; FRANÇA, M. V. S.; SANTOS, J. L. F dos. Atendimento remoto na APS no contexto da COVID-19: a experiência do Ambulatório da Comunidade da Escola Bahiana de Medicina e Saúde Pública em Salvador, Bahia. APS em Revista, Belo Horizonte, v. 2, n. 2, p. 169-176, 2020. DOI: https://doi.org/10.14295/ aps.v2i2.120. Disponível em: https://apsemrevista.org/aps/article/view/120. Acesso em: 20 jun. 2020. 
SILVA JUNIOR, A. G. da et al. V. A experiência de Niterói no enfrentamento da COVID 19: notas preliminares sobre a articulação de políticas sociais e de saúde. APS em Revista, Belo Horizonte, v. 2, n. 2, p. 128-136, 2020. DOI: https://doi. org/10.14295/aps.v2i2.126. Disponível em: https://apsemrevista.org/aps/article/ view/126. Acesso em 20 jul. 2020.

SILVEIRA, R. P. da et al. Telemonitoramento da COVID-19 com participação de estudantes de medicina: experiência na coordenação do cuidado em Rio Branco, Acre. APS em Revista, Belo Horizonte, v. 2, n. 2, p. 151-161, 2020. DOI: 10.14295/ aps.v2i2.121. Disponível em: https://apsemrevista.org/aps/article/view/121. Acesso em: 25 set. 2020.

SILVEIRA, J. P. M. da; ZONTA, R. Experiência de reorganização da APS para o enfrentamento da COVID-19 em Florianópolis. APS em Revista, Belo Horizonte, v. 2 , n. 2, p. 91-96, 2020. DOI: https://doi.org/10.14295/aps.v2i2.122. Disponível em: https://apsemrevista.org/aps/article/view/122. Acesso em: 30 jun. 2020.

SOCHAS, L.; CHANNON, A. A.; NAM, S. Counting indirect crisis-related deaths in the context of a low-resilience health system: the case of maternal and neonatal health during the Ebola epidemic in Sierra Leone. Health Policy and Planning, Oxford, v. 32, supl. 3, p. iii32-iii39, 2017. Disponível em: http://academic.oup.com/ heapol/article/32/suppl_3/iii32/4621472. Acesso em: 25 set. 2020.

STARFIELD, B.; SHI, L.; MACINKO, J. Contribution of Primary Care to Health Systems and Health. The Milbank Quarterly, New York, v. 83, n. 3, p. 457-502, 2005. Disponível em: http://doi.wiley.com/10.1111/j.1468-0009.2005.00409.x. Acesso em: 25 set. 2020.

SUK, J. E. et al. Post-Ebola Measles Outbreak in Lola, Guinea, JanuaryJune 20151. Emerging Infectious Diseases, Atlanta, v. 22, n. 6, p. 1106-1108, 2016. Disponível em: http://wwwnc.cdc.gov/eid/article/22/6/15-1652_article.htm. Acesso em: 25 set. 2020.

TRETHEWEY, S. P.; BECK, K. J.; SYMONDS, R. F. Video consultations in UK primary care in response to the COVID-19 pandemic. British Journal of General Practice, London, v. 70, n. 694, p. 228-229, 2020.

VALE, E. P do et al. Reorganização da Rede de Atenção à Saúde para o enfrentamento da COVID-19 no município de Canaã dos Carajás, Pará. APS em Revista, Belo Horizonte, v. 2, n. 2, p. 83-90, 2020. DOI: https://doi.org/10.14295/ aps.v2i2.101. Disponível em: https://apsemrevista.org/aps/article/view/101. Acesso em: 25 set. 2020. 
VERHOEVEN, V. et al. Impact of the COVID-19 pandemic on the core functions of primary care: Will the cure be worse than the disease? A qualitative interview study in Flemish GPs. BMJ Open, Londron, v. 10, n. 6, p. 1-9, 2020.

VITÓRIA, A. M.; CAMPOS, G. W. de S. Só com APS forte o sistema pode ser capaz de achatar a curva de crescimento da pandemia e garantir suficiência de leitos UTI. 2020. Disponível em: http://www.cosemssp.org.br/wp-content/uploads/2020/04/ So-APS-forte-para-ter-leitos-UTI-.pdf. Acesso em: 22 set. 2020.

WORLD HEALTH ORGANIZATION - WHO. UNITED NATIONS CHILDREN'S FUND UNICEF. Community-based health care, including outreach and campaigns, in the context of the COVID-19 pandemic. Genebra 2020. Disponível em: https:// www.who.int/publications/i/item/WHO-2019-nCoV-Comm_health_care-2020.1. Acesso em: 25 set. 2020.

WORLD HEALTH ORGANIZATION - WHO. Framework for decision-making: implementation of mass vaccination campaigns in the context of COVID-19. Genebra, 2020a. Disponível em: https://www.who.int/publications/i/item/ framework-for-decision-making-implementation-of-mass-vaccination-campaignsin-the-context-of-covid-19. Acesso em: 29 set. 2020.

WORLD HEALTH ORGANIZATION - WHO. Statement on the fourth meeting of the International Health Regulations (2005) Emergency Committee regarding the outbreak of coronavirus disease (COVID-19). Genebra, 2020b. Disponível em: https://www.who.int/news-room/detail/01-08-2020-statement-on-thefourth-meeting-of-the-international-health-regulations-(2005)-emergencycommittee-regarding-the-outbreak-of-coronavirus-disease-(covid-19). Acesso em: 25 set. 2020.

WILHELM, J. A.; HELLERINGER, S. Utilization of non-Ebola health care services during Ebola outbreaks: A systematic review and meta-analysis. Journal of Global Health, Edinburgo, v. 9, n. 1, 2019.

WILLIAMS, S.; TSILIGIANNI, L. COVID-19 poses novel challenges for global primary care. NPJ Primary Care Respiratory Medicine, Londron, v. 30, n. 1, p. 30, 2020.

WILSON, C. G.; RAMAGE, M.; FAGAN, E. B. A Primary Care Response to COVID-19 for Patients with an Opioid Use Disorder. The Journal of Rural Health, Oxford, 2020.

ZHONGQING, X. Self-care of medical staff in primary care: An issue that needs attention during the COVID-19 outbreak. Australian journal of general practice, Melbourne, v. 49, 2020. 
ZIEDAN, E.; SIMON, K.; COADY, W. Effects of State COVID-19 Closure Policy on NON-COVID-19 Health Care Utilization. NBER Working Paper Series, National Bureau of Economic Research, Cambridge, p. 1-68, 2020. 